\title{
Are there efficacious treatments for treating the fatigue-sleep disturbance-depression symptom cluster in breast cancer patients? A Rapid Evidence Assessment of the Literature (REAL ${ }^{\odot}$ )
}

\author{
This article was published in the following Dove Press journal: \\ Breast Cancer:Targets and Therapy \\ 2 September 2015 \\ Number of times this article has been viewed
}

\section{Shamini Jain' \\ Courtney Boyd ${ }^{2}$ \\ Lavinia Fiorentino' \\ Raheleh Khorsan ${ }^{3}$ \\ Cindy Crawford ${ }^{2}$}

'Department of Psychiatry, University of California San Diego, San Diego,

CA, USA; ${ }^{2}$ Samueli Institute, Alexandria, VA, USA; ${ }^{3}$ Samueli Institute, Corona Del Mar, CA, USA
Correspondence: Shamini Jain

Department of Psychiatry, University of California San Diego, 200 Gilman Drive, La Jolla, CA 92093-0818, USA

Email sjain@ucsd.edu
Purpose: While fatigue, sleep disturbance, and depression often co-occur in breast cancer patients, treatment efficacy for this symptom cluster is unknown. A systematic review was conducted to determine whether there are specific interventions (ie, medical, pharmacological, behavioral, psychological, and complementary medicine approaches) that are effective in mitigating the fatigue-sleep disturbance-depression symptom cluster in breast cancer patients, using the Rapid Evidence Assessment of the Literature $\left(\mathrm{REAL}^{\circ}\right)$ process.

Methods: Peer-reviewed literature was searched across multiple databases; from database inception - October 2011, using keywords pre-identified to capture randomized controlled trials (RCT) relevant to the research question. Methodological bias was assessed using the Scottish Intercollegiate Guidelines Network (SIGN) 50 checklist. Confidence in the estimate of effect and assessment of safety were also evaluated across the categories of included interventions via the Grading of Recommendations, Assessment, Development and Evaluations (GRADE) methodology.

Results: The initial search yielded 531 citations, of which 41 met the inclusion criteria. Of these, twelve RCTs reported on all three symptoms, and eight of these were able to be included in the GRADE analysis. The remaining 29 RCTs reported on two symptoms. Studies were of mixed quality and many were underpowered. Overall, results suggest that there is: 1) promising evidence for the effectiveness of various treatment types in mitigating sleep disturbance in breast cancer patients; 2) mixed evidence for fatigue; 3) little evidence for treating depression; and 4) no clear evidence that treatment of one symptom results in effective treatment for other symptoms.

Conclusion: More high-quality studies are needed to determine the impact of varied treatments in mitigating the fatigue-sleep disturbance-depression symptom cluster in breast cancer patients. Furthermore, we encourage future studies to examine the psychometric and clinical validity of the hypothesized relationship between the symptoms in the fatigue-sleep disturbancedepression symptom cluster.

Keywords: fatigue, sleep disturbance, depression, symptom cluster, breast cancer, Rapid Evidence Assessment of the Literature

\section{Introduction}

Treatments for breast cancer presently provide more hope than ever in terms of treating the cancer and reducing mortality. For nearly all women in the US, with the exception of Native American/Alaska Natives, breast cancer mortality continues to decline, ${ }^{1}$ suggesting that our methods of screening and treatment are steadily improving for breast cancer treatment. While survival rates for breast cancer patients continue to improve, behavioral and psychosocial side effects from breast cancer and its treatment 
remain a large problem for these patients, impacting their day-to-day functioning as well as quality of life. Among the most common complaints reported by breast cancer patients during and after treatment are fatigue, sleep disturbance, and depression. These symptoms have often been found to co-occur in breast cancer populations both during and after treatment. ${ }^{2-4}$ The co-occurrence of these and other related symptoms in breast and other cancers has spurred lively discussion about the existence of symptom clusters; an area of study that is relatively in its infancy with no consistent clinical or psychometric measurements. ${ }^{5,6}$

The etiology of each of these symptoms as well as the potential reasons for their co-occurrence is complex, with psychosocial and physical functioning, type of cancer treatment, and medical diagnostic variables all potentially playing roles in both the onset and maintenance of these symptoms. Current evidence suggests that inflammatory and neuroendocrine dysregulation are associated with, and may help perpetuate the co-occurrence of these symptoms within cancer and other populations, ${ }^{7-9}$ through a process often termed "sickness behavior". ${ }^{10}$ Chronic low-grade inflammation (which is thought to be primarily initiated by the cancer and some forms of cancer treatment) facilitates the manifestation of behavioral symptoms including sleep disturbance, fatigue, and depression in the patient. Evidence also suggests that the occurrence and perpetuation of sickness behavior responses to cancer and cancer treatment may be moderated by dispositional factors, including genetic polymorphisms in genes regulating inflammatory responses ${ }^{11}$ and premorbid psychosocial functioning. ${ }^{12}$

While mechanistic research efforts continue to elucidate the pathophysiology underlying the co-occurrence and persistence of these symptoms, there is consistent evidence that a greater number of co-occurrence of symptoms leads to poorer quality of life, ${ }^{13}$ increased neuropathic pain, ${ }^{14}$ and impaired overall functioning ${ }^{15}$ in breast cancer patients. It is therefore important to understand what types of treatments may be most successful not only in treating one symptom, but in potentially successfully treating symptoms that co-occur. Finding interventions that efficiently treat symptom clusters may yield better outcomes for patients as well as lead to greater cost-efficiency in terms of providing interventions that may target more than one symptom.

To our knowledge, there are no systematic reviews exploring the treatments for the co-occurring symptoms of fatigue, sleep disturbance, and depression in breast cancer patients and survivors. We conducted a systematic review to examine which treatments are the most efficacious for treating the fatigue-sleep disturbance-depression symptom cluster in breast cancer patients. The specific objectives of this review were to: 1) survey the literature on treatments addressing at least two of the three symptoms in the fatiguesleep disturbance-depression symptom cluster; 2) examine and assess the quantity, quality and efficacy based on studies as reported in the literature; 3 ) characterize the treatments as behavioral, psychosocial, complementary/alternative medicine (CAM), medical, or pharmacological to better compare treatment types; 4) critically evaluate the efficacy and safety of interventions that examined the impact on the three symptoms based on the literature; and 5) identify gap areas that exist in the literature in order to suggest next steps in research based on our analysis of the pooled literature.

\section{Methods}

To conduct this systematic review, we utilized the Rapid Evidence Assessment of the Literature $\left(\operatorname{REAL}^{\circ}\right.$; Samueli Institute, Alexandria, VA, USA) methodology, which is an expedient approach for conducting systematic reviews. ${ }^{16,17}$ REAL $^{\odot}$ reviews primarily focus on synthesis of peer-reviewed randomized controlled trials (RCTs) published in the English language, and utilize searching across multiple databases. Details on the $\mathrm{REAL}^{\odot}$ methodology for this review are described to follow.

\section{Search strategy}

The following databases were searched from database inception through October 2011: PubMed, EMBASE, CINAHL, Cochrane, and PsycINFO. The following four initial searches, as entered into PubMed, were combined to produce the final search: 1) (breast cancer) and (depression or depress* or "negative affect" or "negative mood"); 2) (breast cancer) and (fatigue or "vital exhaustion"); 3) (breast cancer) and ("sleep disturbance" or "insomnia" or "sleep disruption" or sleep); and 4) (breast cancer) and ("symptom cluster"). The Medical Subject Headings (MeSH) terms and explosions across the terms were applied where applicable and relevant; where MeSH did not apply, variations of the search strategy were used. As this $\mathrm{REAL}^{\odot}$ focused on the fatigue-sleep disturbance-depression cluster components, we considered the terms depressed mood, dysthymia, negative affect, emotional distress and negative mood to be synonymous with depression; insomnia and sleep disruption synonymous with sleep disturbance; and vital exhaustion and cancer-related fatigue synonymous with fatigue. The complete search strategies in each of the databases searched can be obtained by contacting the primary author.

\section{Inclusion/exclusion criteria}

The inclusion criteria were developed in accordance with the Population, Intervention, Control, and Outcome ${ }^{18}$ (PICO) 
framework. Articles were included if they met the following criteria: 1) RCT study design; 2) population consisting of active patients and/or survivors of breast cancer who participated in any treatment intervention; and 3) included at least two of the three cluster symptoms of fatigue, sleep disturbance, and depression (as defined via the search strategy).

Two screeners (CL, RK) screened titles and abstracts for relevance based on the inclusion criteria. Once sufficient inter-rater reliability (Cohen's Kappa $>88 \%$ ) was achieved, the screeners screened the remaining articles independently, resolving arising queries through discussion with either the review manager (CC) and/or the subject matter experts (SMEs; SJ, LF).

\section{Quality assessment and data extraction}

Methodological quality of the included studies was assessed by two reviewers (CL, RK) using the Scottish Intercollegiate Guidelines Network (SIGN 50) checklist for RCTs, a widely accepted, reliable, and validated assessment tool ${ }^{19}$ (see Figure 1). The reviewers were fully trained in the methodology.

The following information was extracted from each included study: population; initial sample and dropout rates; treatment and control interventions; relevant outcomes and results; the reporting and severity of adverse events; the informed consent process; power calculations; effect sizes; and author's main conclusions.

\begin{tabular}{|l|l|}
\hline \multicolumn{2}{|l|}{ Section 1 Internal validity* } \\
\hline Item & Description \\
\hline 1.1 & The study addresses appropriate and clearly focused question \\
\hline 1.2 & The assignment of subjects to treatment groups is randomized \\
\hline 1.3 & An adequate concealment method is used \\
\hline 1.4 & Subjects and investigators are kept blind about treatment allocation \\
\hline 1.5 & The treatment and control groups are similar at the start of the trial \\
\hline 1.6 & The only difference between groups is the treatment under investigation \\
\hline 1.7 & All relevant outcomes are measured in a standard, valid and reliable way \\
\hline 1.8 & $\begin{array}{l}\text { What percentage of subjects in each treatment arm dropped out before the study was } \\
\text { completed? }\end{array}$ \\
\hline 1.9 & $\begin{array}{l}\text { All subjects are analyzed in the groups to which they were randomly allocated (intention } \\
\text { to treat analysis) }\end{array}$ \\
\hline 1.10 & Where the study is carried out at more than one site, results are comparable for all sites \\
\hline Each item in section 1 is to be evaluated using these criteria: \\
(i) \\
(ii) & $\begin{array}{l}\text { Adeqll covered } \\
\text { (iii) }\end{array}$ \\
(iv) & Noorly addressed applicable (NA) only for questions 1.4, 1.6, 1.10 \\
\hline
\end{tabular}

\begin{tabular}{|l|l|}
\hline \multicolumn{2}{|l|}{ Section 2 Overall assessment } \\
\hline Score options:,,+++- based on following (modifications to SIGN 50 criteria in italics): \\
\hline++ & $\begin{array}{l}\text { All or most of the criteria have been fulfilled. Where they have not been fulfilled the } \\
\text { conclusions of the study are thought very unlikely to alter. An article receives this score if } \\
\text { there are } 0 \text { criteria scored as poorly addressed }\end{array}$ \\
\hline+ & $\begin{array}{l}\text { Some of the criteria have been fulfilled. Those criteria that have not been fulfilled or not } \\
\text { adequately described are thought unlikely to alter the conclusions. An article receives this } \\
\text { score if } 1-3 \text { criteria are scored as poorly addressed }\end{array}$ \\
\hline- & $\begin{array}{l}\text { Few or no criteria fulfilled. The conclusions of the study are thought likely or very likely to } \\
\text { alter. An article receives this score if more than } 3 \text { criteria are scored as poorly addressed }\end{array}$ \\
\hline
\end{tabular}

Figure I SIGN 50 checklist for RCT Study Design.

Note: Adapted from Scottish Intercollegiate Guidelines Network (SIGN). A Guideline Developer's Handbook. Edinburgh: SIGN; 200 I. (SIGN publication no. 50). [cited 24 June 20I4]. Available from URL: http://www.sign.ac.uk. ${ }^{19}$ Adapted from Crawford C, Wallerstedt DB, Khorsan R, Clausen SS, Jonas WB, Walter JA. A systematic review of biopsychosocial training programs for the self-management of emotional stress: potential applications for the military. Evid Based Complement Alternat Med. $2013 ; 747694$. Epub 2013 Sep $23 .{ }^{72}$

Abbreviations: RCT, randomized controlled trial; SIGN, Scottish Intercollegiate Guidelines Network. 
Patients were grouped into the following categories: non-metastatic, metastatic, mixed (ie, population included both metastatic and non-metastatic patients), and survivors (those who were no longer receiving active treatment). Treatment interventions were grouped into the following categories: behavioral (eg, exercise), psychosocial (eg, cognitive-behavioral therapy and supportive counseling), CAM (eg, yoga and herbal medicine), medical procedures (eg, radiation, ovarian ablation), or pharmacological (eg, anti-depressants).

\section{Data synthesis and analysis}

Once the quality assessment of individual studies was completed, two SMEs (SJ and LF) performed a quality assessment of the overall literature pool for each treatment intervention and patient population using a modified version of the Grading of Recommendation Assessment, Development and Evaluation (GRADE), an internationally accepted approach to grading the quality of evidence and strength of recommendations. ${ }^{20}$ SMEs used the GRADE to examine the results of the review for each population and treatment type in order to: 1) examine the confidence in and magnitude of the estimate of the effect; 2) assign a safety grade; and 3) develop recommendations (such as strong or weak recommendations in favor of or against the use of such treatments) for the included literature pool based on the $\mathrm{REAL}^{\circ}$ results. The SMEs received formal training in the modified GRADE, conducted the GRADE independently, and then met as a team to resolve any discrepancies and come to consensus on overall recommendations.

\section{Results}

The main objective of this systematic review was to focus on the three symptom cluster for breast cancer. However, due to our comprehensive search strategy, the authors also found several articles that focused on two of the three symptoms. Due to resources and the main objective of this review however, the authors only report on the three symptom cluster in detail assessing the overall literature pool to come up with recommendations using GRADE methodology. The authors share the two symptom cluster studies in Table 1 as a frame of reference only and hope to perform future analysis of these studies in the future. The studies on two symptoms can be found in Table $1^{21-49}$ and three symptoms in Table 2. ${ }^{50-61}$

Of the 531 citations yielded from the database searches, 41 RCTs fit the inclusion criteria and were subsequently included in the quality assessment and data extraction phase of the $\mathrm{REAL}^{\odot}$. Of these, $29 \mathrm{RCT}^{\mathrm{T}}$ reported on two component clusters; Table 1 categorizes these by treatment type and population, and reports their individual characteristics and overall SIGN 50 scores. The remaining twelve RCTs reported on all three component clusters (Table 2), eight of which were able to be included in the GRADE analysis (Figure 2).

Both Tables 1 and 2 categorize studies according to treatment type (behavioral, CAM, medical procedures, psychosocial, or pharmacological) and across four population types including non-metastatic, metastatic, mixed (comprised of both non-metastatic and metastatic patients), and survivors.

\section{Characteristics of included studies Methodological quality of included studies according to SIGN 50 criteria}

According to SIGN 50 criteria $^{19}$ (see Figure 1), the majority $(63.4 \%)$ of the studies received an overall SIGN 50 score of + (high quality), with the remaining (26.8\%) articles receiving scores of - (low quality), and fewer $(9.8 \%)$ receiving a score of ++ (excellent quality).

Most of the 41 RCTs $(92.6 \%)$ included in the review addressed an appropriate and clearly focused question either well or adequately. Almost half of the articles addressed randomization poorly $(46.3 \%$ ), with $22.0 \%$ of articles doing so adequately, and $31.7 \%$ doing so well. The majority of articles (65.8\%) poorly addressed allocation concealment, with less than a third of articles addressing this criterion either well $(22.0 \%)$ or adequately $(12.2 \%)$. Baseline similarities between treatment and control groups were well addressed in the majority of articles $(70.7 \%)$ with a small percentage of studies addressing it adequately (19.5\%) or poorly $(9.8 \%)$. Outcome reliability and validity was addressed well by $41.4 \%$ of articles with the remaining articles addressing this criterion adequately $(22.0 \%)$ or poorly $(36.6 \%)$. Although many studies $(53.7 \%)$ reported attrition rates adequately or well, many articles also poorly addressed intention-to-treat analyses (46.3\%).

Three criteria, blinding, treatment group differences, and multi-site differences, were not applicable to all studies (ie, blinding not possible, treatment groups are too inherently different from each other, study only conducted at one site). Consequently, we only assessed the articles where these criteria were applicable. Of the twelve RCTs where blinding was possible, blinding of treatment allocation was addressed well and adequately in $41.7 \%$ and $25.0 \%$ of the studies, respectively; approximately $33.3 \%$ of these studies addressed this criterion poorly. We were able to assess twelve RCTs for treatment difference between groups; many of these articles did so either well $(33.3 \%)$ or adequately (41.7\%), with 
$25.0 \%$ of the articles doing so poorly. Lastly, only a small number of studies $(n=12)$ were conducted at multiple sites; the majority of these poorly addressed (66.6\%) similarity of site results, with the remaining articles doing either well $(16.7 \%)$ or adequately $(16.7 \%)$.

\section{Safety assessment}

Of the 41 articles included in our review, only 16 reported on adverse events with four studies $s^{30,36,46,55}$ reporting no adverse events. Ten studies reported adverse events including gastrointestinal problems, ${ }^{31,32,43,53}$ dizziness, ${ }^{31,32}$ changes in blood pressure,${ }^{31,34,60}$ weakness, ${ }^{31}$ anemia, ${ }^{32}$ pain/discomfort, ${ }^{24,34,47}$ headache, ${ }^{43,60}$ insomnia, ${ }^{53}$ palpitations,${ }^{53}$ anxiety, ${ }^{53}$ skin rashes and angioedema, ${ }^{51}$ jaundice/liver damage, ${ }^{51}$ dry mouth, ${ }^{21}$ changes in taste, ${ }^{21,51}$ and disease progression. ${ }^{24}$ Additionally, two studies ${ }^{22,23}$ reported adverse events occurred but did not describe them.

\section{GRADE analysis}

The GRADE analysis was conducted on studies addressing all three symptoms (fatigue, sleep disturbance, and depression) in order to provide recommendations regarding treatment of the symptom cluster as a whole. While we present the tables on studies that examined two of the three symptoms to familiarize the reader with the breadth of literature available on examining intervention effects on co-occurring symptoms within this cluster, as our primary interest was on examining studies that investigated effects on the symptom cluster as defined by sleep disturbance, depressed mood, and fatigue, we chose to conduct the GRADE on studies that examined these three symptoms. There were twelve RCTs that addressed all three symptoms that were included in this review; of these, one study ${ }^{50}$ (examining a psychosocial intervention) reported results in metastatic breast cancer patients, five studies (two examining behavioral interventions, ${ }^{54,55}$ two examining medical interventions, ${ }^{51,52}$ and one examining a CAM intervention) ${ }^{53}$ reported results in non-metastatic breast cancer patients, three studies (two examining psychosocial interventions, ${ }^{57,58}$ one examining a pharmacological intervention) ${ }^{56}$ reported results in mixed (metastatic and non-metastatic) breast cancer patients, and three studies (two examining pharmacological interventions, ${ }^{59,60}$ one examining a CAM intervention) ${ }^{61}$ reported results on survivors (patients who had completed adjuvant or neo-adjuvant treatment).

Because GRADE analyses require at least two studies per category, only eight of these three RCTs addressing three symptoms were included in the final analysis; four studies $^{50,53,56,61}$ were excluded because they were the only studies in their respective categories (ie, CAM treatment for non-metastatic and survivor populations, pharmacological treatment for mixed population, psychosocial treatment for metastatic population).

The GRADE results are presented in Table 3 and briefly summarized below. In this GRADE synthesis, we noted that most studies did not report effect sizes, nor describe the presence or absence of adverse events. Our final GRADE recommendations, therefore, are given considering these major omissions of reporting in the reviewed studies.

\section{Non-metastatic population \\ Behavioral treatment}

Two studies ${ }^{54,55}$ comparing walking exercise programs to usual care in a non-metastatic population, were poor (-) quality and reported improvements in sleep disturbance, but no significant differences for depression. Results were mixed for fatigue symptoms, as one study ${ }^{55}$ reported improvement in fatigue levels while the second study ${ }^{54}$ reported no such differences. Adverse events were only discussed in one study, ${ }^{55}$ which reported no adverse events. Because effect sizes were not reported, and both the quality and power of these studies was low, no recommendation could be given for this treatment type.

\section{Medical treatment}

Two studies ${ }^{51,52}$ examined medical procedures as treatment options for reducing fatigue, sleep disturbance, and depression in this population. The higher $(+)$ quality study, ${ }^{51}$ comparing radiotherapy to no radiotherapy, reported improvements in insomnia with radiotherapy, but no significant differences between groups for depression and fatigue. The second study ${ }^{52}$ was of poor (-) quality, and compared ovarian ablation with chemotherapy. This study reported lower levels of fatigue, sleep disturbance, and depression in the ovarian ablation versus chemotherapy group. Effect sizes were not reported in either study, and only one study ${ }^{51}$ reported adverse events (such as skin rashes, angioedema, taste changes, jaundice, and liver damage). Consequently, a weak recommendation in favor was given for the usage of medical treatment methods for impacting the symptoms examined for this population.

\section{CAM treatment}

There was only one study (of high $[++]$ quality) ${ }^{53}$ examining a CAM treatment in a non-metastatic population. Although fatigue and sleep disturbance symptoms were improved following administration of the herbal compound guarana, 
Table I Characteristics and SIGN 50 score of included studies, grouped by population and treatment type, that address two cluster components $(\mathrm{n}=29)$

\begin{tabular}{|c|c|c|c|c|}
\hline Citation & Cluster & Population description & Description of intervention & Description of control \\
\hline \multicolumn{5}{|l|}{ Metastatic } \\
\hline \multicolumn{5}{|c|}{ Pharmacological } \\
\hline $\begin{array}{l}\text { Bottomley } \\
\text { et } \mathrm{al}^{21}\end{array}$ & $\begin{array}{l}\text { Fatigue, } \\
\text { sleep } \\
\text { disturbance }\end{array}$ & $\begin{array}{l}275 \text { patients with } \\
\text { metastatic breast cancer } \\
\text { patients }{ }^{\text {b }} \text { with a median } \\
\text { age of } 53 \text { years }(C) \\
\text { and } 52 \text { years }(T) \\
(S D=N D)\end{array}$ & $\begin{array}{l}\text { Doxorubicin } 60 \mathrm{mg} / \mathrm{m}^{2} \text { as an iv bolus plus } \\
\text { paclitaxel } 175 \mathrm{mg} / \mathrm{m}^{2} \text { as a } 3-\mathrm{hr} \text { infusion } \\
\text { Assessment time points: } 2 \text { wks pre-intervention, } \\
\text { midpoint (cycles } 2,4 \text {, and } 6 \text { ) and EoT ( } 3 \text { mons } \\
\text { after the last cycle, with a time window of } 10 \text { wks) }\end{array}$ & $\begin{array}{l}\text { Doxorubicin } 60 \mathrm{mg} / \mathrm{m}^{2} \text { plus } \\
\text { cyclophosphamide } \\
600 \mathrm{mg} / \mathrm{m}^{2}\end{array}$ \\
\hline $\begin{array}{l}\text { Svensson } \\
\text { et } \mathrm{al}^{22}\end{array}$ & $\begin{array}{l}\text { Fatigue, } \\
\text { sleep } \\
\text { disturbance }\end{array}$ & $\begin{array}{l}287 \text { female metastatic } \\
\text { breast cancer patients } \\
(\leq \text { Stage II) } \\
(\text { mean age }=\text { ND) }\end{array}$ & $\begin{array}{l}\text { ET (epirubicin plus paclitaxel): } \\
\text { Epirubicin } 75 \mathrm{mg} / \mathrm{m}^{2} \text { by iv infusion } \\
\text { Assessment time points: baseline, } 2 \text { mons, } \\
\text { and } 9 \text { mons }\end{array}$ & $\begin{array}{l}\text { TEX (epirubicin plus paclitaxel } \\
\text { plus capecitabine): Epirubicin } \\
75 \mathrm{mg} / \mathrm{m}^{2} \text { by iv infusion } \\
\text { Both groups were offered } \\
2 \text { nd line treatment with oral } \\
\text { capecitabine when the disease } \\
\text { progressed }\end{array}$ \\
\hline $\begin{array}{l}\text { Hakamies- } \\
\text { Blomqvist } \\
\text { et } \text { al }^{23}\end{array}$ & $\begin{array}{l}\text { Fatigue, } \\
\text { sleep } \\
\text { disturbance }\end{array}$ & $\begin{array}{l}283 \text { female metastatic } \\
\text { breast cancer patients }{ }^{d} \\
\text { with a mean age of } \\
52.13 \text { years }(\mathrm{T}) \text { and } \\
52.16 \text { (C) }\end{array}$ & $\begin{array}{l}\text { Docetaxel } 100 \mathrm{mg} / \mathrm{m}^{2} \\
\text { Assessment time points: baseline and before } \\
\text { each treatment (cycles } 2-6)\end{array}$ & $\begin{array}{l}\text { MF: sequential methotrexate } \\
\text { and } 5 \text {-fluorouracil at } \\
200 \mathrm{mg} / \mathrm{m}^{2} \text { and } 600 \mathrm{mg} / \mathrm{m}^{2} \\
\text { respectively }\end{array}$ \\
\hline Diel et $\mathrm{al}^{24}$ & $\begin{array}{l}\text { Fatigue, } \\
\text { sleep } \\
\text { disturbance }\end{array}$ & $\begin{array}{l}466 \text { female breast cancer } \\
\text { patients }^{\text {d }}(\text { Stage }=\text { ND) } \\
\text { with a mean age of } \\
54.5 \pm I I .5(\mathrm{C}), 55.3 \pm 10.9 \\
(2 \mathrm{MGIBT}) \text { and } 56.1 \pm \mathrm{I} 1.4 \\
(6 \mathrm{MGIBT}) \text { years }\end{array}$ & $\begin{array}{l}\text { 2MGIBT: Ibandronate } 2 \mathrm{mg} \text { by iv bolus injection } \\
6 \text { MGIBT: Ibandronate } 6 \mathrm{mg} \text { by iv infusion } \\
\text { Assessment time points: baseline, day before each } \\
\text { study visit (Visits } 2-5,8, \mathrm{II}, 14,17,20,23,26 \text { ) }\end{array}$ & Placebo \\
\hline Geels et $\mathrm{al}^{25}$ & $\begin{array}{l}\text { Depression, } \\
\text { sleep } \\
\text { disturbance }\end{array}$ & $\begin{array}{l}300 \text { female breast cancer }^{\mathrm{s}} \\
\text { patients }{ }^{\mathrm{b}} \text { (Stage and } \\
\text { mean age }=\mathrm{ND})\end{array}$ & $\begin{array}{l}\text { Doxorubicin } 40 \mathrm{mg} \text { by iv } \\
\text { Assessment time points: baseline and every } 3 \text { wks } \\
\text { (Ist day of each new cycle) }\end{array}$ & Doxorubicin $60 \mathrm{mg}$ by iv \\
\hline
\end{tabular}

Psychosocial

\begin{tabular}{|c|c|c|}
\hline $\begin{array}{l}\text { Bordeleau } \\
\text { et } \mathrm{al}^{26}\end{array}$ & $\begin{array}{l}\text { Fatigue, } \\
\text { sleep } \\
\text { disturbance }\end{array}$ & $\begin{array}{l}215 \text { female metastatic } \\
\text { breast cancer patients } \\
\text { with a mean age of } \\
49.4 \pm 8.4(\mathrm{~T}) \text { and } \\
51.5 \pm 10.0(\mathrm{C}) \text { years }\end{array}$ \\
\hline $\begin{array}{l}\text { Williams } \\
\text { and } \\
\text { Schreier }{ }^{27}\end{array}$ & $\begin{array}{l}\text { Fatigue, } \\
\text { sleep } \\
\text { disturbance }\end{array}$ & $\begin{array}{l}\text { 7I breast cancer patients } \\
\text { ( } \leq \text { Stage } 4) \text { with a mean } \\
\text { age of } 50.39(T) \text { and } \\
50.42(C) \text { years, } \\
(S D=N D)\end{array}$ \\
\hline
\end{tabular}

Low et $\mathrm{al}^{28} \quad$ Depression $\quad 62$ female breast cancer sleep, $\quad$ patients ${ }^{\text {h }}$ (Stage IV) with disturbance a mean age of $53.8 \pm 10.3$ years
Supportive-expressive therapy (SET): Supportive-expressive therapy receiving UC plus educational materials about breast cancer and its treatment, relaxation, and nutrition.

Assessment time points: baseline, 4 mons, 8 mons, and FU ( 12 mons)

Audiotape on self-care behaviors and SE (SCB): 20-min audiotape that consisted of education about exercise and relaxation to manage anxiety, fatigue, and sleep problems

Assessment time points: I-mon, 3 mons
UC plus educational materials about treatment, relaxation, and nutrition at every 6 mons

Received the standard education and care given to all patients during $\mathrm{CHT}$
Emotional writing (EMO): Participants wrote at home about cancer-related emotions Assessment time points: baseline, 3 mons
Control Writing Condition (CTL): Writing facts about diagnosis and treatment 
Intervention duration

Relevant outcomes assessed/results

Adverse events

Quality

Every 3 wks for a max of 6 cycles.

ET: 30-min infusion followed by a 3-hr infusion with paclitaxel $175 \mathrm{mg} / \mathrm{m}^{2}$ TEX: 30-min infusion followed by a 3-hr infusion with paclitaxel $155 \mathrm{mg} / \mathrm{m}^{2}$. Oral capecitabine $825 \mathrm{mg} / \mathrm{m}^{2}$ given $2 \times$ daily for 14 days; both treatments repeated every 3 wks for 9 mons. TD: Every 3 wks until treatment cycle 6

MF: Given at days I and 8 every

3 wks until treatment cycle 6

2MGIBT: iv over I-2 hr at 3-4 wkly intervals limited to a max of 24 treatments for 96 wks 6MGIBT: iv over $\mathrm{I}-2 \mathrm{hr}$ at $3-4$ wkly intervals limited to a max of 24 treatments for 96 wks ID $40: 40 \mathrm{mg} / \mathrm{m}^{2}$ (day I) plus iv vinorelbine $20 \mathrm{mg} / \mathrm{m}^{2}$ (days I and 8) at every 3 wks ID60: $60 \mathrm{mg} / \mathrm{m}^{2}$ day I at every 3 wks

SET: wkly 90-min therapist-led support group + participated in 2-day workshops every 9-12 mons and received monthly reviews of videotapes of randomly selected sessions.

The subjects were instructed to listen to the audiotape 12-24 $\mathrm{hr}$ before the start of $\mathrm{CHT}$ cycles and as often as desired during the course of their treatment.

$4 \times 20$ min sessions for 3 wks
EORTC QLQ-C30 (Fatigue): No significant difference between arms (NS). Across time, fatigue $\uparrow$ in both arms by the 2 nd assessment. Fatigue $\downarrow$ for $C$ arm to levels comparable with baseline. Fatigue remained moderately clinically meaningful in T arm but NS. EORTC QLQ-C30 (Sleep Disturbance): No significant difference between arms or across time (NS).

EORTC QLQ-C30 (Fatigue): The ET arm scored clinically $\downarrow$ than TEX on fatigue at the 2 mons assessment but NS.

EORTC QLQ-C30 (Sleep Disturbance): A small clinical difference was found for insomnia in favor of the TEX at the 2 and 9 mons assessments but NS.

EORTC QLQ-C30 (Fatigue): At EoT, TD suffered $\uparrow$ fatigue compared to MF $(P=0.04)$.

EORTC QLQ-C30 (Sleep Disturbance): At EoT, the TD suffered $\uparrow$ from insomnia compared to MF $(P=0.04)$.

EORTC QLC-C30 (Fatigue): For 6MGIBT, fatigue had $\downarrow$ significantly $(P<0.05)$ at the EoT compared with placebo. EORTC QLC-C30 (Sleep Disturbance): Insomnia $\downarrow$ in the 6 MGIBT compared with placebo, but NS.

EORTC QLQ-C30 (Depression):: $60.3 \%$ patients showed $\downarrow$ depression scores, $26.3 \%$ were stable and $13.4 \%$ worsened. A positive relationship between likelihood of improvement and objective tumor response $(P=0.046)$.

EORTC QLQ-C30 (Sleep Disturbance): Clinical $\downarrow$ in sleep disturbance but no significant difference between arms or across time (NS). CRF (Insomnia): Clinical $\downarrow$ in insomnia but no significant difference between arms or across time (NS).

EORTC QLC-C30 (Fatigue)': A significant across-time deterioration (time effect) in fatigue regardless of study arm $(P=0.003)$.

EORTC QLC-C30 (Sleep Disturbance): There were no significant differences across-time (NS).

SCD (Fatigue): There were no significant differences between SCB and control in severity of SE for fatigue (NS). Higher percentage in the control arm than in the SECA arm reported fatigue. The fatigue severity ratings significantly $\uparrow$ from the Ist SCD to the 2 nd SCD for both arms. Overall fatigue remained a troublesome SE during the study.

SCD (Sleep Disturbance): There were no significant differences between the arms in severity of SEs for sleep disturbance (NS). More women in control than in the SCB arm reported difficulty in sleeping whereas the severity significantly increased between the Ist SCD and the 2nd SCD for both arms but NS.

CES-D (Depression): No differences between arms or across time (NS).

PSQI (Sleep Disturbance): No differences between arms or across time (NS).
More headaches, + feeling unwell, dry mouth, and food tasting unusual in both groups Yes but ND $+$

Yes but ND

Disease progression, bone pain, and spontaneous bone fracture-

ND

ND 
Table I (Continued)

\begin{tabular}{|c|c|c|c|c|}
\hline Citation & Cluster & Population description & Description of intervention & Description of control \\
\hline \multicolumn{5}{|c|}{ Multi-modal lifestyle } \\
\hline Targ and & Fatigue, & I8I female breast cancer & CAM program (CAM): Intensive lifestyle change & Standard Program (SP): \\
\hline \multirow[t]{4}{*}{ Levine $^{29}$} & depression & patients $^{f}(\leq$ Stage IV $)$ & and group support program with an emphasis & I.5 hrs/wk unstructured \\
\hline & & with a mean age of & on psychospiritual issues, and inner process & psycho-educational support \\
\hline & & $49 \pm 8.6(\mathrm{~T})$ and & Assessment time points: pre-test, post-test & group led by a psychologist \\
\hline & & $47 \pm 8.8(\mathrm{C})$ years & & $\begin{array}{l}\text { with emphasis on coping with } \\
\text { real life issues }\end{array}$ \\
\hline
\end{tabular}

Non-metastatic

Medical procedures

Bonnema Depression, I39 female breast et $\mathrm{al}^{30} \quad$ sleep cancer ${ }^{\mathrm{a}}$ patients disturbance ( $\leq$ Stage II) with a mean age $=\mathrm{ND}$

\section{Behavioral}

$\begin{array}{lll}\begin{array}{l}\text { Courneya } \\ \text { et } \mathrm{al}^{31}\end{array} & \begin{array}{l}\text { Fatigue, } \\ \text { depression }\end{array} & \begin{array}{l}242 \text { breast cancer } \\ \text { patients }\end{array} \\ & & \text { with a mean age of } \\ & & 49.2 \text { years, }(\mathrm{SD}=\mathrm{ND})\end{array}$

$\begin{array}{lll}\text { Wang et } \mathrm{al}^{32} & \begin{array}{l}\text { Fatigue, } \\ \text { sleep }\end{array} & \begin{array}{l}72 \text { Taiwanese breast } \\ \text { cancer patients }\end{array} \\ \text { disturbance }(\leq \text { Stage II) } & \text { with a mean age of } \\ & 48.40 \pm 10.15 \text { years }(\mathrm{T}) \\ & \text { and } 52.30 \pm 8.84 \text { years }(\mathrm{C})\end{array}$

Mock et $\mathrm{al}^{33} \quad$ Fatigue, depression

52 female breast cancer patients $^{d}$ ( $\leq$ Stage III) with a mean age of $47.14 \pm 11.72$ years (LW) and $48.64 \pm 10.69(\mathrm{HW})$ years
Short hospital stay: Evaluating the medical and psychosocial effects of short hospital stays after surgery for breast cancer

Assessment time points: Baseline, I-mon after surgery EoT (4 mons); During outpatient visits

Aerobic exercise (AET): Exercise on a cycle ergometer, treadmill, or elliptical Resistance exercise (RET): Exercise performing two sets of 8-12 reps included leg extension, leg curl, leg press, calf raises, chest press, seated row, triceps extension, biceps curls, and modified curl-ups Assessment Time Points: baseline ( $1-2$ wks after starting $\mathrm{CHT}$ ), midpoint (middle of $\mathrm{CHT}$ ), EoT (3-4 wks after CHT), and FU (6 mons) BSET-based: Home-based self-efficacy related exercise (walking) program Assessment Time Points: baseline ( $24 \mathrm{hrs}$ prior to the surgery), 24 hrs prior to the day of the one cycle of CHT (2-3 wks after surgery), day of expected nadir (7-10 days after CHT), and EoT (6 wks) Low walk (LW): $<90$ min of walking/wk + adjuvant $\mathrm{CT}$ or RT after breast cancer surgery High walk (HW): $>90$ min of walking/wk + adjuvant CT or RT after breast cancer surgery. Assessment time points: baseline, 6 wks of RT, and EoT (during 4-6 mons of adjuvant $\mathrm{CHT}$ )

\section{CAM}

\begin{tabular}{|c|c|c|}
\hline Listing et $\mathrm{a}^{34}$ & $\begin{array}{l}\text { Fatigue, } \\
\text { depression }\end{array}$ & $\begin{array}{l}34 \text { female breast cancer } \\
\text { patients }^{d}(\leq \text { Stage II) } \\
\text { with a mean age of } \\
59.2 \pm I 2.1 \text { (T) and } \\
59.9 \pm I I .5(\mathrm{C}) \text { years }\end{array}$ \\
\hline Listing et $\mathrm{al}^{35}$ & $\begin{array}{l}\text { Fatigue, } \\
\text { depression }\end{array}$ & $\begin{array}{l}\text { II } 5 \text { female breast cancer } \\
\text { patients }(\leq \text { Stage II) } \\
\text { with a mean age of } \\
57.6 \pm 10.8 \text { years }(T) \\
\text { and } 6 I .4 \pm 10.9 \text { years }(C)\end{array}$ \\
\hline $\begin{array}{l}\text { da Costa } \\
\text { et } \mathrm{al}^{36}\end{array}$ & $\begin{array}{l}\text { Fatigue, } \\
\text { depression }\end{array}$ & $\begin{array}{l}36 \text { breast cancer patients } \\
\text { ( } \leq \text { Stage II) with a mean } \\
\text { age of } 59(A) \text { and } 57(B) \\
\text { years, }(S D=N D)\end{array}$ \\
\hline
\end{tabular}

Classical massage (CM): Swedish techniques while subjects were in prone position

Assessment time points: baseline, 5 wks; and FU (II wks)

Classical massage: Standardized Swedish techniques on back, neck and head

Assessment time points: baseline (TI),

EoT (5-wks;T2), and FU (II wks;T3)

Guarana A: Guarana extract daily; before beginning 14th $R T$, group switched to placebo for remainder of study Guarana B: Received placebo; before beginning 14th RT, group switched guarana daily for remainder of study Assessment time points: Beginning of RT, midpoint of RT, (before the I4th RT session), and EoT (last session of RT or 28th session)
Long Hospital Stay: Effects of long hospital stay after surgery for breast cancer

UC: Offered a I-mon exercise program after post intervention assessment

UC

UC

No treatment: wait list

UC: waiting list

Placebo: crossover 


Intervention duration
2/wk for 2.5 hrs each time; each wk
included I hr health series; 90 mins of
dance/movement program; experiential
work; and 90 min discussion group
led by a licensed clinical social for
a total of 12 wks.

At admission, patients were given a daily diary, to be used for I mon, and a wkly diary to be used for the next 3 mons for a total 4 mons. The length of hospital stay was recorded.

AET: $3 \times /$ wk for $\sim 4$ wks: duration began at $15 \mathrm{~min}$ for wks $\mathrm{I}-3$. It $\uparrow$ by $5 \mathrm{~min}$ every 3 wks until the duration reached $45 \mathrm{~min}$ at $\mathrm{wk} 18$. RET: $3 \times /$ wk: performing 2 sets of 8-12 reps of 9 different exercises. Resistance was $\uparrow$ by 10\% when participants completed more than 12 reps at wk 18. Low to moderate intensity exercise per wk, and at least 30 mins per session or the accumulation of $10-\mathrm{min}$ sessions to reach 30 mins for 6 wks.

6 wks of RT and 4-6 mons of CT. Most exercise prescriptions began at 10-15 mins per session and 5-6 sessions per wk. Subjects were advanced to 30 mins per session, 5-6 daily sessions per wk.

$30 \mathrm{~min} /$ day for 5 wks plus FU.

$2 \times 30 \mathrm{~min} / \mathrm{wk}$ for 5 wks plus FU.

$75 \mathrm{mg}$ of guarana extract daily for last session of RT or 28th session.

Relevant outcomes assessed/results

Adverse events

Quality

POMS (Depression): Both the CAM arm $(P<0.004)$ and control

ND

$+$ $(P<0.02)$ showed a significant $\downarrow$ in depression at EoT. POMS (Fatigue): No significant difference between arms or across time (NS).

VDBP (Sleep Disturbance): No differences between arms at EoT (NS).

VDBP (Depression): No differences between arms at EoT (NS).

FACT-A (Fatigue): No differences between AET, RET and UC arms (NS). However, for AET adherence $(P=0.002)$ had greater mean changes at EoT compared to UC.

CES-D (Depression): No differences between AET, RET and UC arms (NS). However, for adherence to AET $(P=0.003)$ and RET $(P=0.019)$ had greater mean changes at EoT compared to UC; no differences between arms at FU (NS).

Effect Size: 0.30

FACIT-F (Fatigue)': Fatigue $\downarrow$ in the BSET arm with significant differences between arms at time-3 $(P=0.00 \mathrm{I})$ and at EoT $(P=0.00 \mathrm{I})$.

PSQI (Sleep Disturbance): BSET had significantly $\downarrow$ sleep disturbances than those in control over the intervention period $(P=0.006)$.

POMS (Fatigue)': HW had significantly $\downarrow$ fatigue at EoT compared to $\operatorname{LW}(P=0.00 \mathrm{I})$.

POMS (Depression): $\mathrm{HW}$ had significantly $\downarrow$ depression

at EoT compared to LW $(P=0.03)$.

Diary (Fatigue): Mean fatigue on the daily diaries was significantly $\downarrow$ for the HW compared to LW $(P=0.00 \mathrm{I})$. CHT was significantly $\uparrow$ than $\mathrm{RT}(P=0.0 \mathrm{I})$.

PFS (Fatigue Total Score)i: HW had $\downarrow$ total fatigue at EoT compared to LW but not NS.

BSF (Tiredness): No differences between arms at EoT (NS); $C M$ had $\downarrow$ levels of tiredness compared to control at FU $(P<0.01)$. BSF (Anxious Depression)i: CM had $\downarrow$ levels of anxious depression compared to control at EoT $(P=0.03)$; no differences between arms at FU (NS).

BSF (Anxious Depression): Anxious depressions between arms were NS. BFS (Tiredness): Tiredness between arms was NS.

GBB (Fatigue): Fatigue was $\downarrow$ at the EoT between arms but was NS. This positive effect was sustained over time and achieved significance compared with control at FU $(P=0.048)$.

Effect Size: 0.3

CFS (Fatigue): Fatigue between all arms was NS. MDA BFI (Fatigue): Fatigue between all arms was NS BDI-II (Depression): Depression between all arms was NS.

Lightheaded,
hypotensive,
moderately
nauseous $(\mathrm{n}=\mathrm{I})$,
experienced
dizziness,
weakness and
mild diarrhea
( $\mathrm{n}=\mathrm{I})$
Anemia and
dizziness with
dyspnea $(\mathrm{n}=2)$

ND

Higher level of $\quad++$ back pain $(n=l)$, increase in blood pressure $(n=l)$

ND

None 
Table I (Continued)

\begin{tabular}{|c|c|c|c|c|}
\hline Citation & Cluster & Population description & Description of intervention & Description of control \\
\hline \multicolumn{5}{|l|}{ Psychosocial } \\
\hline Berger et $\mathrm{al}^{37}$ & $\begin{array}{l}\text { Fatigue, } \\
\text { sleep } \\
\text { disturbance }\end{array}$ & $\begin{array}{l}219 \text { female breast cancer } \\
\text { patients }(\leq \text { Stage IIIA) } \\
\text { with a mean age of } \\
52.13 \text { years }(T) \text { and } \\
52.16(C),(S D=N D)\end{array}$ & $\begin{array}{l}\text { Behavioral therapy (BT): Individualized sleep } \\
\text { promotion plan (ISPPr): Modified stimulus control, } \\
\text { modified sleep restriction, relaxation therapy, } \\
\text { and sleep hygiene } \\
\text { Assessment time points: Baseline ( } 2 \text { days prior CT), } \\
\text { during the } 7 \text { days after each treatment, and FU } \\
\text { ( } 30 \text { days after the last treatment) }\end{array}$ & $\begin{array}{l}\text { HEC: Healthy Eating Control } \\
\text { received healthy eating } \\
\text { information and attention }\end{array}$ \\
\hline $\begin{array}{l}\text { Cohen and } \\
\text { Fried }^{38}\end{array}$ & $\begin{array}{l}\text { Fatigue, } \\
\text { sleep } \\
\text { disturbance }\end{array}$ & $\begin{array}{l}\text { I } 54 \text { female early-stage } \\
\text { breast cancer patients }^{d} \\
\text { ( } \leq \text { Stage II) with a mean } \\
\text { age of } 55.9 \pm 10.4 \text { (CBT), } \\
51.8 \pm I I .6 \text { (RGI), and } \\
52.9 \pm I I .8 \text { (C) years }\end{array}$ & $\begin{array}{l}\text { Cognitive behavior (CBT): cognitive and } \\
\text { behavioral strategies } \\
\text { Relaxation and guided imagery (RGI): } \\
\text { systematic learning of deep RGI plus deep } \\
\text { breathing and autogenic relaxation } \\
\text { Assessment time points: preintervention, } \\
\text { EoT ( } 3 \text { mons), and FU ( } 4 \text { mons) }\end{array}$ & UC \\
\hline Badger et al ${ }^{39}$ & $\begin{array}{l}\text { Fatigue, } \\
\text { depression }\end{array}$ & $\begin{array}{l}48 \text { female breast cancer } \\
\text { patients }^{f}(\leq \text { Stage III) } \\
\text { with a mean age of } \\
53.04 \pm 8.72(\mathrm{~T}) \text { and } \\
54.7 \mathrm{I} \pm 10.34(\mathrm{C}) \text { years }\end{array}$ & $\begin{array}{l}\text { Telephone interpersonal counseling (TIPC): telephone } \\
\text { calls from a nurse counselor; sessions focused } \\
\text { on issues such as cancer education, interpersonal role } \\
\text { disputes, social support, awareness, management } \\
\text { of depressive symptoms, and role transitions } \\
\text { Assessment time points: baseline, post-intervention } \\
\text { (wk 6), and FU (wk I0) }\end{array}$ & $\begin{array}{l}\text { Usual Care Attentional } \\
\text { Control Group (UC): calls } \\
\text { from nurse counselor and } \\
3 \text { calls for partner plus } \\
\text { resource list }\end{array}$ \\
\hline $\begin{array}{l}\text { Sandgren } \\
\text { et } \mathrm{al}^{40}\end{array}$ & $\begin{array}{l}\text { Fatigue, } \\
\text { depression }\end{array}$ & $\begin{array}{l}62 \text { female breast cancer } \\
\text { patients }^{d}(\leq \text { Stage II) } \\
\text { with a mean age of } \\
51.23 \pm 12.5 \text { years }\end{array}$ & $\begin{array}{l}\text { Telephone therapy: therapy included providing } \\
\text { support, teaching coping skills, managing anxiety } \\
\text { and stress, and helping to solve patient-generated } \\
\text { problems (eg, interpersonal problems, problems } \\
\text { returning to work) } \\
\text { Assessment time points: baseline, } 4 \text { mons, } 10 \text { mons }\end{array}$ & No treatment \\
\hline $\begin{array}{l}\text { Dolbeault } \\
\text { et } \mathrm{al}^{4 !}\end{array}$ & $\begin{array}{l}\text { Fatigue, } \\
\text { depression }\end{array}$ & $\begin{array}{l}203 \text { breast cancer } \\
\text { patients }{ }^{\mathrm{b}} \text { with a mean } \\
\text { age of } 54.5 \pm 9.3(\mathrm{~T}) \\
\text { and } 51.6 \pm 9.6(\mathrm{C}) \text { years }\end{array}$ & $\begin{array}{l}\text { Psychoeducationally structured model (PSM): } \\
\text { Based on CBT principles, exercises were initiations } \\
\text { combined with general medical information and peer } \\
\text { exchanges on defined themes; } 8-12 \text { participants, } \\
\text { led by } 2 \text { psychologists or psychiatrists } \\
\text { Assessment time points: I-wk pre-intervention, } \\
\text { EoT ( } 8 \text { wks), and FU (I-wk pre-deferred intervention) }\end{array}$ & Wait list \\
\hline \multicolumn{5}{|c|}{ Multimodal lifestyle } \\
\hline $\begin{array}{l}\text { Lindemalm } \\
\text { et } \mathrm{al}^{42}\end{array}$ & $\begin{array}{l}\text { Fatigue, } \\
\text { depression }\end{array}$ & $\begin{array}{l}4 \text { I female low-stage } \\
\text { breast cancer patients }{ }^{d} \\
\text { with a mean age of } \\
56.5(T) \text { and } 66 \text { years }(C), \\
\text { (Stage and SD = ND) }\end{array}$ & $\begin{array}{l}\text { Support group program CT-RT: Support team + } \\
\text { adjuvant-combined CT and RT } \\
\text { Support Group Program RT: Support team + } \\
\text { adjuvant RT only } \\
\text { Assessment time points: Pre-intervention, } \\
\text { and FU ( } 2 \text { mons, } 6 \text { mons, } 12 \text { mons) }\end{array}$ & UC \\
\hline
\end{tabular}




Intervention duration
Prior to the initial CT, BT participants
developed an ISPP plan that was regularly
reinforced and revised for 30 days after
the last CT, compared with scores prior
to the initial treatment. HEC group
participants received equal time
and attention at each home visit.

$9 \times 90 \mathrm{~min}$ sessions/wk for 3 mons plus FU

6 wkly sessions for 6 wks plus FU

I/wk for 4 wks and then every other wk for 10 mons; phone sessions lasted up to 30 mins

$8 \times 2$ hr sessions/wk for 8 wks pus FU

From Sunday to Saturday on a residential basis followed by 4-days and FU (2 mons after initial visit)
Relevant outcomes assessed/results

Adverse events

Quality

PFS (Fatigue): Fatigue in both arms changed over time, with $\uparrow$ during the treatments and $\downarrow$ after treatments ended $(P=0.00 \mathrm{I})$. The fatigue pattern was similar between the BT and HEC arms (NS).

PSQI (Sleep): Significant changes in sleep quality in the arms over time $(P=0.003)$. A group by time interaction was found $(P=0.04)$. Sleep quality $\uparrow$ significantly in BT arm, but sleep of the HEC arm was more disturbed at treatment 4 and remained more disturbed at FU.

Diary (Sleep): Significant $\downarrow$ number of awakenings ( $P=0.032$ ), $\downarrow$ WASO-M $(P=0.027)$, and $\uparrow$ sleep efficiency $P=0.00 I)$ in the BT arm over time. But sleep efficiency favoring BT was significant between arms $(P=0.075)$.

Effect size: 0.17

FSI (Fatigue symptoms): Mean of fatigue symptoms $\downarrow$ in both intervention arms $(P<0.001)$ but only the reduction in the RGI arm from pre-to-post intervention appeared significant. Fatigue remained significantly $\downarrow$ in the RGI arm than in CB and UC, $(P<0.01)$.

Effect Size $=0.20 \mathrm{MSQ}$ (Sleep difficulties): Mean of sleep difficulties $\downarrow$ in both intervention arms $(P<0.001)$, but only the reduction in the RGI arm from pre-to-post intervention appeared significant. Sleep difficulties remained significantly $\downarrow$ in the RGI arm than in $C B$ and $U C(P<0.00 I)$.

Effect Size: 0.10

CES-D (Depression): No difference between arms or across time (NS).

PANAS (Negative Affect): No difference between arms or across time (NS).

MFI (Fatigue)i: No significant main effect existed for time. However, a trend was found in the time by group interaction that indicate a $\downarrow$ for TIPC arm but not for those in control but NS $(P=0.09)$.

POMS (Fatigue): No difference between arms or across time (NS). POMS (Depression): No difference between arms or across time (NS).

POMS (Depression)i: PSM had $\downarrow$ levels of depression compared to control $(P<0.05)$; depression scores $\downarrow$ over time in both arms $(P<0.05)$.

POMS (Fatigue): Greater $\downarrow$ of fatigue in the PSM arm compared to control $(P<0.0 \mathrm{I})$. EORTC QLQ-C30 (Fatigue): Greater $\downarrow$ of fatigue in the PSM arm compared to control $(P<0.0 \mathrm{I})$. POMS Global (Negative Affect)': A greater reduction of negative effects were observed in the TG compared with the CG arm but NS.

NFQ (Fatigue) q: No difference between arms (NS); both arms showed significant $\downarrow$ of total fatigue $(P=0.0 \mathrm{I})$ and physical fatigue $(P=0.015)$ over time compared to control.

HADS (Depression)q: No differences between arms or across time (NS).
ND

ND

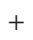

ND $+$

ND $+$

ND $+$ ND 
Table I (Continued)

\begin{tabular}{|c|c|c|c|c|}
\hline Citation & Cluster & Population description & Description of intervention & Description of control \\
\hline \multicolumn{5}{|l|}{ Mixed } \\
\hline \multicolumn{5}{|c|}{ Pharmacological } \\
\hline Roscoe & Fatigue, & 122 female breast cancer & Paroxetine: $20 \mathrm{mg}$ & Placebo \\
\hline \multirow[t]{4}{*}{ et $\mathrm{al}^{43}$} & depression & patients $^{\mathrm{b}}($ Stage $=$ ND) & Assessment time points: Cycle $\mathrm{I}-4$ of $\mathrm{CHT}$ & \\
\hline & & with a mean age of & & \\
\hline & & $52.2 \pm 9.3(\mathrm{~T})$ and & & \\
\hline & & $52.2 \pm 10.2(\mathrm{C})$ years & & \\
\hline
\end{tabular}

\section{Psychosocial}

$\begin{array}{ll}\text { Thornton } & \text { Fatigue, } \\ \text { et } \mathrm{al}^{44} & \text { depression }\end{array}$

Sandgren and Fatigue, $\mathrm{McCaul}^{49}$ depression

Sandgren and Fatigue, $\mathrm{McCaul}^{45} \quad$ sleep disturbance

237 female breast cancer patients $^{d}$ ( $\leq$ Stage III) with a mean age of 54.4 years, $(S D=N D)$

\section{5 female breast cancer patients $^{d}$ (Stage II, III) with a mean age of $50 \pm \mathrm{II} .6(\mathrm{C})$ and $50 \pm 8.6(\mathrm{~T})$ years}

235 female breast cancer with a mean age of $54.5 \pm 11.8$ years patients $^{d}$ ( $\leq$ Stage III)

Survivors

\section{CAM}

Jain et $\mathrm{al}^{46} \quad$ Fatigue, depression

76 breast cancer survivors ( $\leq$ Stage IIIA) with a mean age of $52(\mathrm{BH}), 52(\mathrm{MH})$ and $19(C)$ years, $(\mathrm{SD}=\mathrm{ND})$
Psychological intervention: conducted in groups of 8-12 patients led by two psychologists; Assessment time points: baseline, 4 mons, 8 mons, 12 mons

Cancer health education (CHE): Structured curriculum presented by the nurse with time for brief discussion and questions.

Emotional expression therapy (EET): Same number of calls from the same nurses; nurses instructed patients to feel free to explore their emotions and the things that are on their mind Assessment time points: pre-intervention, and FU: approx 5-mons

Health education group (HET): topics included: I) understanding breast cancer, 2) managing post-surgical changes, 3) understanding treatment, 4) managing treatment side effects and fatigue, 5) healthy lifestyle, and 6) FU review. Emotional expression therapy (EET): nurse instructed patients to describe their thoughts and feelings about breast cancer, and any emotional issues about breast cancer Assessment time points: pre-test, 6 mons, 13 mons

Biofield healing $(\mathrm{BH})$ : practitioner practices hands-on healing with standard hand positions for 45-60 min (energy chelation technique)

Mock healing $(\mathrm{MH})$ : delivered by practitioners who were skeptical scientists trained to use the identical hand placements as biofield healing practitioners Assessment time points: pre-intervention, postsession 2, midpoint, post-session 6, and EoT (4 wks)
No treatment: not restricted from participating in community support groups, receiving mental health care or using standard clinic nurse helpline

Waitlist 
Daily starting 7 days after Ist on-study treatment (Ist cycle of CHT) and stopping 7 days after 4 th on-study treatment (4th cycle of $\mathrm{CHT}$ )

Two sessions over 12 mons consisting of 4 mons of $1.5 \mathrm{hr}$ sessions (intensive phase) followed by 8 monthly sessions (maintenance phase)

Both interventions: $5 \times 30 \mathrm{~min}$ phone calls/wk, plus 6th FU call at 3 mons

Both interventions: $5 \times 30$ min phone calls/wk, plus 6 th FU call at 3 mons. Seven oncology nurses delivered both interventions for a total 13 mons

Two sessions $/$ wk $\times 4$ wks
CES-D (Depression)i: Paroxetine had greater effective than control in $\downarrow$ depression across all CHT cycles $(P<0.001)$; paroxetine arm $(P<0.0 \mathrm{I})$ showed a significant $\downarrow$ in depression between treatments $I$ and 4 while control showed no significant differences (NS). POMS-DD (Depression): Paroxetine $(P<0.0 \mathrm{I})$ and control $(P=0.03)$ both showed significant $\uparrow$ in depression between treatments $I$ and 4 POMS-FI (Fatigue): There were no significant differences between arms at any time point (NS).

FSCL (Fatigue): There were no significant differences between arms at any time point (NS).

MAF (Fatigue): There were no significant differences between arms at any time point (NS).

CES-D (Depression): Depression symptoms $\downarrow$ faster over time for psychological arm when compared to control $(P<0.04)$. POMS (Depression): Depression $\downarrow$ faster over time for psychological arm when compared to control $(P=0.02)$. POMS (Fatigue): The psychological arm showed greater $\downarrow$ in fatigue over time when compared to control $(P=0.048)$ POMS (Fatigue): No differences between the CHE, EET, and control arms (NS); pooled analyses show no differences across time (NS).

POMS (Depression): No differences between the CHE, EET, and control arms (NS), pooled analyses show an improvement in depressed scores over time $(P<0.01)$.

POMS (Depression): No differences between the HET, EET and control arms (NS), combined group scores show a decrease in depression over time $(P<0.03)$.

POMS (Fatigue): No differences between the HET, EET and control arms (NS), combined group scores show a $\downarrow$ in fatigue over time $(P<0.03)$.
Nausea and headache

ND $+$

ND $+$

ND $+$

None $\quad++$
MFI (Fatigue): Both the BH $(P<0.0005)$ and MH $(P=0.02)$

arms had a greater $\downarrow$ in fatigue symptoms than the control. There were no significant changes in fatigue for control (NS).

Effect size: Biofield healing vs Control $(d=1.04)$,

Mock healing versus control $(d=0.68)$

CES-D (Depression): There were no significant interactions (NS). 
Table I (Continued)

\begin{tabular}{|c|c|c|c|c|}
\hline Citation & Cluster & Population description & Description of intervention & Description of control \\
\hline \multicolumn{5}{|c|}{ Behavioral } \\
\hline Lee et $\mathrm{al}^{47}$ & $\begin{array}{l}\text { Fatigue, } \\
\text { depression }\end{array}$ & $\begin{array}{l}50 \text { breast cancer } \\
\text { survivors with a mean } \\
\text { age of } 47.5 \pm 5.1 \text { (SSEP), } \\
45.6 \pm 7.0 \text { (GEP) and } \\
47.6 \pm 9.2 \text { (C) years }\end{array}$ & $\begin{array}{l}\text { Both training interventions: include stretching } \\
\text { and strengthening } \\
\text { Scapula-oriented shoulder exercise program (SSEP): } \\
\text { Adopted from scapular mobilization exercises for } \\
\text { shoulder dyskinesis and kinetic chain-based shoulder } \\
\text { rehabilitation. Participants were asked to do exercises } \\
\text { from simple motions to advanced strengthening. } \\
\text { General Exercise Program (GEP): regular exercise } \\
\text { program for shoulder and whole body } \\
\text { Assessment time points: I and } 4 \text { wks after } \\
\text { the EoT for 8-wks }\end{array}$ & $\begin{array}{l}\text { UC: A leaflet guiding self-care } \\
\text { including general shoulder } \\
\text { range of motion exercise after } \\
\text { surgery was provided as a UC }\end{array}$ \\
\hline \multicolumn{5}{|c|}{ Multimodal lifestyle } \\
\hline Kim et $\mathrm{al}^{48}$ & $\begin{array}{l}\text { Fatigue, } \\
\text { depression }\end{array}$ & $\begin{array}{l}45 \text { female breast cancer } \\
(\leq \text { Stage III) survivors } \\
\text { with a mean age } \\
\text { of } 44.6 \pm 9.9(\mathrm{~T}) \text { and } \\
47.1 \pm 7.3 \text { (C) years }\end{array}$ & $\begin{array}{l}\text { Simultaneous stage-matched exercise and diet (SSED): } \\
\text { Stage-matched telephone counseling complimented } \\
\text { with a workbook, individualized prescription for } \\
\text { regular moderate exercise, a balanced diet program, } \\
\text { exercise and diet prescriptions } \\
\text { Assessment time points: baseline and wk } 12\end{array}$ & ND \\
\hline
\end{tabular}

Notes: $31 \%$ of the studies did not have sufficient statistical power and $41 \%$ of studies did not report a power calculation: ${ }^{a}$ patients receiving surgery; ${ }^{b}$ patients receiving chemotherapy; 'patients receiving radiation; ${ }^{d}$ patients receiving surgery, chemotherapy, and radiation; ${ }^{e}$ patients receiving surgery and chemotherapy; ${ }^{\mathrm{f}} \mathrm{patients}$ receiving chemotherapy and radiation; ${ }^{8}$ patients receiving hormone therapy; ${ }^{h}$ treatment received not described; 'effect size not reported.

Abbreviations: 95\% Cl, 95\% Confidence Interval; BDI, Beck Depression Inventory; BFI, Brief Fatigue Inventory; BSF, Berlin Mood Questionnaire; C, control Group; CBT, Cognitive Behavioral Therapy; CES-D, Center for Epidemiological Studies-Depression Scale; CFS, Chalder Fatigue Scale; CHT, chemotherapy; CRF, Case Report Form; EORTC QLC-C30, European Organization for Research and Treatment of Cancer Health Related Quality of Life Questionnaire; EoT, end of treatment; FACIT-F, Functional Assessment of Chronic Illness Therapy; FACT-A, Functional Assessment of Cancer Therapy-Anemia; FSCL, Fatigue Symptom Checklist; FSI, Fatigue Symptom Inventory; FU, follow-up; GBB, Geissen Complaints Inventory; GHQ, General Health Questionnaire; HADS, Hospital Anxiety Depression Score; HDRS, Hamilton Depression Rating Scale; hr, hour; HSCL-25, Hopkins Symptom Checklist-25; iv, intravenous; ISI, Insomnia Severity Index; MAF, Multidimensional Assessment of Fatigue; Max, maximum; MD, mean difference; MDA BFI, Anderson Brief Fatigue Inventory; MFI, Multidimensional Fatigue Inventory; Min, minutes; Mon(s), month(s); MSQ, Mini Sleep Questionnaire; NCl-CTC, National Cancer Institute Common Toxicity Criteria; ND, not described; NFQ, Norwegian Fatigue Questionnaire; NS, not significant; PANAS, Positive and Negative Affect Scale; PFS, Piper Revised Fatigue Scale; POMS-DD, Monopolar Profile of Mood States; POMS, Profile of Mood States; PSQI, Pittsburgh Sleep Quality Index; QOL, quality of life; RT, radiation therapy; reps, repetitions; SAS, Self-rating Anxiety Scale; SCD, Self Care Diary; SD, standard deviation; SE, side effect; T, treatment group; SIGN, Scottish Intercollegiate Guidelines Network; UC, usual care; VDBP, van den Borne and Pruyn; wk(s), week(s); wkly, weekly.

no such improvements in depression were found. Adverse events including insomnia, palpitations, nausea, and anxiety were reported. Because this was the only study in this treatment and population category, however, it was not included in the GRADE analysis.

\section{Metastatic population}

Psychosocial treatment

One high $(+)$ quality study ${ }^{50}$ investigating psychosocial (cognitive behavioral therapy) treatment for metastatic patients reported mixed results for depression, and null results for fatigue and insomnia. Because this was the only study in this population, it could not be examined via GRADE.

\section{Mixed population}

Psychosocial treatment

Both studies ${ }^{57,58}$ examining psychosocial treatments were of high (+) quality and reported significant improvements in insomnia, no improvements in fatigue and mixed results for depression. Specifically, the first study, ${ }^{57}$ comparing psychosocial support with either a nurse or psychologist to usual care, found significant improvements in insomnia, but no differences for fatigue or depression symptoms. The second study ${ }^{58}$ compared cognitive behavioral therapy to a wait list control. Results showed improvements in both insomnia and depression, but no differences in fatigue. Adverse events were not reported in either study. Given the promising results for sleep improvement in these adequate quality studies, but a lack of information on adverse events, a weak recommendation in favor of psychosocial treatments was given.

\section{Medical treatment}

Although one high (+) quality study ${ }^{56}$ investigating chemotherapy dosages with tamoxifen reported lower fatigue and depression with the lower versus higher dose of chemotherapy, because there was only one study in this category, a GRADE recommendation could not be provided for medical treatments for a mixed population. 


\begin{tabular}{|c|c|c|c|}
\hline Intervention duration & Relevant outcomes assessed/results & Adverse events & Quality \\
\hline $\begin{array}{l}\text { Gradually with an interval } \\
\text { of } 2 \text { wks for a total } 8 \text { wks }\end{array}$ & $\begin{array}{l}\text { EORTC QLQ-C30 (Fatigue): No differences between SSEP, } \\
\text { GEP and control arms (NS); fatigue scores of GEP arm } \downarrow \text { at FU } \\
(P=0.027) \text {; no differences over time were seen in the SSEP (NS) } \\
\text { or control (NS). } \\
\text { BDI (Depression): No significant differences between arms } \\
\text { or across time (NS). }\end{array}$ & $\begin{array}{l}\text { Shoulder } \\
\text { discomfort } \\
\text { (scapula-oriented } \\
\text { exercise group) }\end{array}$ & ++ \\
\hline $\begin{array}{l}\text { Delivered wkly during } 30 \mathrm{~min} \\
\text { telephone counseling session } \\
\text { for } 12 \text { wks }\end{array}$ & $\begin{array}{l}\text { BFI (Fatigue)i: SSED arm had greater } \downarrow \text { in fatigue levels } \\
\text { compared to control }(P=0.00 I) \text {. } \\
\text { HADS (Depression): SSED arm had greater } \downarrow \text { on depression } \\
\text { scores compared to control }(P=0.035) \text {. }\end{array}$ & ND & + \\
\hline
\end{tabular}

\section{Survivor population}

Pharmacological treatment

One high (+) quality and one poor (-) quality study investigating pharmacological treatments cited mixed results for sleep improvement and no improvement in either fatigue or depression. The higher quality study ${ }^{60}$ compared low and high dosages of venlafaxine to placebo and found no significant differences for any of the cluster symptoms. The poor quality study ${ }^{59}$ also did not find differences for depression or fatigue, however, the authors reported improvements in insomnia. Effect sizes were not reported in either of the two studies, and only one study ${ }^{60}$ reported an adverse event (ie, hypertension). Consequently, no recommendation could be given.

\section{CAM treatment}

One high (+) quality CAM study ${ }^{61}$ reported improvements in sleep disturbance and fatigue symptoms of breast cancer survivors following a yoga intervention, but no differences in negative mood. Because this was the only CAM study for a survivor population, however, it was not included in the GRADE analysis.

\section{Discussion}

The purpose of this review was to identify and systematically evaluate the current literature that examined the impact of interventions for the fatigue-sleep disturbancedepression symptom cluster in breast cancer patients and survivors. Of the 41 RCTs included in this review, 29 articles reported on two of the three symptom clusters and twelve reported on all three symptoms. It is important to note that many of these studies did not specify these symptoms as primary aims; in fact, $75 \%$ of the studies with three symptoms did not overtly specify the primary aim, and $58 \%$ of the studies with two symptoms did not specify the primary aim. Many of the studies assessed fatigue and insomnia via the European Organization for Research and Treatment of Cancer Quality of Life questionnaire (EORTC QLQ-30) subscales; while these subscales are considered reliable and valid, they are not as comprehensive in their 
Table 2 Characteristics and SIGN 50 score of included studies, grouped by population and treatment type, that address three cluster components $(n=12)$

\begin{tabular}{|c|c|c|c|}
\hline Citation & Population description & Description of intervention & Description of contro \\
\hline \multicolumn{4}{|l|}{ Metastatic } \\
\hline \multicolumn{4}{|l|}{ Psychosocial } \\
\hline Savard et al ${ }^{50}$ & $\begin{array}{l}45 \text { depressed female breast } \\
\text { cancer patients }^{d}(\leq \text { Stage IV) } \\
\text { with a mean age of } 51.4 \pm 8.05(\mathrm{~T}) \\
\text { and } 51.66 \pm 8.62(\mathrm{C}) \text { years }\end{array}$ & $\begin{array}{l}\text { CBT: Strategies meant for treating depression } \\
\text { including coping strategies identified } \\
\text { Assessment time points: pre-treatment, } \\
\text { EoT ( } 8 \text { wks), and FU: } 3 \text { mons, } 6 \text { mons }\end{array}$ & $\begin{array}{l}\text { Wait list: Waited a } \\
\text { minimum of } 8 \text { wks } \\
\text { before receiving CBT }\end{array}$ \\
\hline
\end{tabular}

Non-metastatic

Medical procedures

Prescott et $\mathrm{al}^{51} \quad 255$ breast cancer ( $\leq$ Stage III)

patients ${ }^{c}$ with a mean age

of $72.3 \pm 5.0(\mathrm{~T})$ and

$72.8 \pm 5.2(\mathrm{C})$ years

Groenvold et al ${ }^{52}$

303 premenopausal breast cancer patients ${ }^{\mathrm{d}}$ with a mean age of $45.0(\mathrm{CHT})$ and 44.4 (ovarian ablation) years

(Stage and SD = ND)

\section{CAM}

de Oliveira

Campos et $\mathrm{al}^{53}$

75 breast cancer patients ${ }^{\mathrm{b}}$ ( $\leq$ Stage III) with a mean age of $50.2 \pm$ I I.95 (Placebo-guarana group) and $51.76 \pm 9.73$ (Guarana-placebo group) years

Behavioral Payne et al $^{54}$
20 female breast cancer patients ${ }^{g}$ receiving hormonal therapy with a mean age of $64.7 \pm 6.3$ years
RT: Standard treatment of postoperative breast irradiation

Assessment time points: baseline, 2 wks, 9 mons, 15 mons

CHT: Intravenous cyclophosphamide, methotrexate, fluouracil

Assessment Time points: I mon, 3 mons, 5 mons, 9 mons, 15 mons, 24 mons

Guarana: Standardized dried extract from P cupana; cornstarch; guarana preparation had a $\mathrm{pH}$ of 4.83 (10\% solution in water), a water content of $3.9 \%$, a concentration of $1.7 \%$ tannins, and $6.46 \%$ caffeine Assessment time points: Day I, Day 2I, Day 49

Exercise: Moderate walking Assessment time points: baseline, 2 wks, 12 wks and EoT (14 wks)
No RT treatment

Ovarian ablation (OA): Pelvic irradiation or surgical oophorectomy

Crossover: Placebo capsules

UC: Standard interaction with nurses, physicians and staff 
Intervention duration

Relevant outcomes assessed/results

Adverse events Quality

CBT: $8 \times 60-90 \mathrm{~min}$ sessions; plus 3 booster sessions administered every 3 wks following treatment during which psychologists reviewed the difficulties the patient had experienced since the last session and the strategies used/could have been used to cope with them

Standard treatment of postoperative breast irradiation for 15 mons total

CHT: Nine cycles given every 3 wks for 2 years Ovarian Ablation: Pelvic irradiation with a total dose of 15 Gy given as 5 daily fractions or surgical oophorectomy for 2 years

Guarana $50 \mathrm{mg}$ by mouth $2 \times$ daily or placebo for 21 days. After a

7-day washout period, patients were crossed over to the opposite experimental arm for 49 days total

$4 \times 20 \mathrm{~min}$ of moderate walking each wk for I 4 wks total
HDRS (Depression): Depression $\downarrow$ over time in the CBT arm $(P<0.000 \mathrm{I})$

but not in the control (NS); combined scores across both arms $\downarrow$ from pre to Eot $(P<0.000 \mathrm{I})$ and from EoT to FU $(P<0.0 \mathrm{I})$.

Effect size: Treatment $(d=-1.8 \mathrm{I} I)$, Control $(d=-0.544)$

BDI (Depression): No differences between arms (NS); combined scores across both arms $\downarrow$ from pre to EoT $(P<0.0001)$ but not from EoT to FU (NS).

Effect size: Treatment ( $d=1.859)$, Control $(d=0.84)$

HADS (Depression): No differences between arms (NS); combined scores across both arms $\downarrow$ from pre to EoT $(P<0.000$ I) but not from EoT to FU (NS). Effect size: Treatment ( $d=-1.82)$, control $(d=-1.30)$

MFI (Fatigue): No differences between arms and across time (NS); combined scores across both arms $\downarrow$ from pre to EoT $(P<0.0$ I) but not from EoT to FU (NS).

Effect size: Treatment ( $d=-0.940)$, control $(d=-0.736)$

ISI (Insomnia): No differences between arms and across time (NS); combined scores across both arms $\downarrow$ from pre to EoT $(P<0.0$ I) but not from EoT to FU (NS).

Effect Size: Treatment ( $d=0.958)$, control $(d=-0.089)$

EORTC QLQ-C30 (Insomnia)': Mean levels of insomnia tended to $\uparrow$ slightly in the control arm, whereas insomnia levels were $\downarrow$ in the RT arm. The treatment difference is statistically significant $(P=0.0 \mathrm{I})$ which remained consistent throughout FU. HADS (Depression): There is evidence of $\uparrow$ depression scores over time $(P=0.04)$, but there is no evidence of a treatment effect. Although the

$\uparrow$ in mean depression scores is significant, the absolute change is small. EORTC QLQ-C30 (Fatigue): There was no evidence of a time, treatment, or time by treatment effect (NS).

EORTC QLQ-C30 (Fatigue): CHT had $\uparrow$ levels of fatigue compared to the OA

arm at 3 mons $(P<0.00 \mathrm{I})$ and 5 mons $(P<0.00 \mathrm{I})$ but not at other time points (NS). EORTC QLQ-C30 (Sleep)i: CHT had $\uparrow$ levels of sleep disturbances at I mon $(P<0.05)$ and 5 mons $(P<0.00 \mathrm{I})$ but not at other time points (NS).

HADS (Depression): $\mathrm{CHT}$ had $\uparrow$ levels of depression at 3 mons $(P<0.05)$ and 5 mons $(P<0.01)$ but not at other time points (NS).

CFS (Fatigue): Guarana arm had $\downarrow$ fatigue compared to placebo on day 2 I $(P<0.0$ I) but not on day 49 (NS).

PSQI (Sleep Disturbance): Guarana group had $\downarrow$ sleep disturbances compared to placebo on day $49(P=0.05)$ but not day 2 I (NS).

BFI (Fatigue): Guarana arm had $\downarrow$ global fatigue compared to placebo on days 2 I and $49(P<0.01)$.

HADS (Depression): No significant difference on depression between arms (NS). FACIT-F (Fatigue Global Scores)': The average of fatigue scores $\downarrow$ from baseline to EoT for the patients receiving guarana for both arms (ie, received guarana first and the group that switched to guarana after receiving placebo) (NS).

PFS(Fatigue): Fatigue levels between arms and across time were NS.

PSQI (Sleep Disturbance) ${ }^{q}$ : PSQI scores in the exercise arm $\downarrow$ significantly over time $(P=0.007)$.

PSQI (Actual Wake Time)': After 12 wks, actual wake time was shorter in the exercise arm compared to control $(P=0.002)$.

PSQI (Actual Sleep Time): After 12 wks, actual sleep time was shorter in the exercise arm compared to control $(P=0.005)$.

PSQI (Movement During Sleep)': After 12 wks, exercise showed less movement during sleep compared to control $(P=0.002)$.

PSQI (Sleep Efficiency): No differences between arms (NS).

CES-D (Depression): No difference between arms or over time (NS).
ND $+$

Skin rashes, angioedema, taste changes, jaundice and liver damage

ND

Insomnia, palpitations, nausea, anxiety

ND 
Table 2 (Continued)

\begin{tabular}{ll}
\hline Citation & Population description \\
\hline Mock et al ${ }^{55}$ & 50 women with early stage \\
& breast cancer ${ }^{\mathrm{c}}(\leq$ stage II) \\
& a mean age of 49 years, \\
& $48.09 \pm 5.42$ years $(\mathrm{T})$ and \\
& $50.29 \pm 8.47$ (C)
\end{tabular}

\section{Mixed}

Pharmacological van Dam et al ${ }^{56}$

104 female breast cancer patients $^{\mathrm{d}}$ (S Stage III) with a mean age of $45.5 \pm 6.2$ (CTC), $48.1 \pm 6.8$ (FEV) and $46.1 \pm 5.2(\mathrm{C})$ years

Psychosocial Arving et al ${ }^{57}$

179 breast cancer patients ${ }^{\mathrm{d}}$ ( $\leq$ Stage N0) with a mean age of 55 years, $(S D=N D)$

Savard et $\mathrm{al}^{58}$

58 female breast cancer patients $^{d}$ ( $\leq$ Stage III) with a mean age of $54.8 \mathrm{I} \pm 7.0 \mathrm{I}(\mathrm{T})$ and $53.37 \pm 7.72(\mathrm{C})$ years

\section{Survivors}

Pharmacological

Fahlen et al $^{59}$

75 female breast cancer survivors ${ }^{8}$ with a mean age of $57.0 \pm 5.6$ years age of $50.5 \pm 8.7$ years

Description of intervention

Exercise: Individualized, home-based

walking program

Assessment time points: baseline

(before or during the first days of radiation therapy), end of 3-wks and end of radiation therapy (about 6 wks)

CTC: High-risk breast cancer who were treated with high-dose $\mathrm{CHT}$ plus tamoxifen FEV: High-risk breast cancer who were treated with standard-dose $\mathrm{CHT}$ plus tamoxifen Assessment time points: ND

Psychosocial support with nurse (INS): Carried out by two oncology nurses specially trained in psychosocial support including lectures covering knowledge and skills to assess and treat common psychosocial problems in cancer patients.

Psychosocial support with psychologist (IPS):

Delivered by two psychologists with theoretical knowledge about cancer diseases and treatment, and had experience of counseling Assessment time points: baseline, I-mon, 3 mons, 6 mons CBT: Combined approach combining behavioral and educational strategies Assessment time points: baseline, EoT ( $8 \mathrm{wks})$, and FU: 3 mons, 6 mons, 12 mons
Description of control

UC

No treatment

UC: regular contact with patient's oncologist and medical staff

Wait List: waited a minimum of 8 wks before receiving $\mathrm{CBT}$
Menopausal hormone therapy (HT):

Estradiol $2 \mathrm{mg}$ and progestogen

Assessment time points: baseline, 6 mons, 12 mons
No HT

Placebo: Crossover
Low dose: Venlafaxine

High dose: Additional dose of venlafaxine Assessment Time points: baseline, wkly for 14 wks, and FU: I mon, 6 mons, 12 mons 


\begin{tabular}{|c|c|c|c|}
\hline Intervention duration & Relevant outcomes assessed/results & Adverse events & Quality \\
\hline Self-paced, progressive & SAS (Fatigue): Fatigue levels significantly $\downarrow$ between arms and across time $(P=0.0 \mid 8)$. & None & - \\
\hline program, with $20-30 \mathrm{~min}$ & SAS (Sleep Disturbance) $)^{q}$ : Sleep disturbance $\downarrow$ significantly between arms & & \\
\hline brisk walk increments & and across time $(P=0.027)$ & & \\
\hline followed by 5 -min slow & PFS (Fatigue): Fatigue $\downarrow$ significantly between arms and across time $(P=0.00 \mathrm{I})$. & & \\
\hline walk for 6 wks total & SAS (Depression): Depression between arms and across time were NS. & & \\
\hline
\end{tabular}

In both the CTC and the FEV arms, the patients were treated with tamoxifen ( $40 \mathrm{mg}$ periorally once/day) for 2 years

Participants met for $4 \times 3 \mathrm{hr}$ wkly lessons. Between meetings, they met to train assessment and techniques.

FU discussions were held at termination and 5 mons later

Participants met for $8 \times 90$ min wkly sessions offered in groups of 4-6 patients for 8 wks total; FU carried out 3, 6, and 12 mons after the treatment
EORTC QLQ-C30 (Fatigue): CTC reported being $\uparrow$ fatigued than patients in the control $(P=0.025)$.

EORTC QLQ-C30 (Sleep Disturbance): No significant difference between arms or across time (NS).

HSCL-25 (Depression): CTC had significantly elevated scores on the depression subscale in comparison with the patients in the control $(P=0.04 \mathrm{I})$.

EORTC QLQ-C30 (Insomnia)': Both intervention arms improved significantly more than the $U C$ arm regarding insomnia $(P<0.01)$. There were significant differences between arms with INS having the greatest $\downarrow$ in insomnia,

followed by IPS and UC arm $(P<0.05)$.

EORTC QLQ-C30 (Fatigue): No differences in fatigue between INS,

IPS and control arms (NS).

HADS (Depression): No differences in depression between INS, IPS and control arms (NS); no differences across time (NS).

ISI, Sleep Diary, Insomnia Interview Schedule (Insomnia): CBT arm showed great improvement compared to control on total sleep time $(P<0.00$ I), sleep onset latency $(P<0.05)$, wake after sleep onset $(P<0.00 I)$, and ISI $(P<0.05)$; pooled analyses show a significant improvement from pre to EoT on all sleep variables $(P<0.01)$; improvements were maintained from EoT to FU for all variables except total sleep time $(P<0.05)$ and ISI (filled out by significant other; $P<0.05)$ which showed further improvement. HADS (Depression): : Depression $\downarrow$ over time only in the CBT arm $(P<0.01)$; pooled analyses showed a significant improvement in depression scores from pre to EoT $(P<0.00 \mathrm{I})$; improvements were maintained from EoT to FU (NS). MFI (Fatigue): No differences between arms (NS); pooled analyses showed a significant improvement in fatigue scores from pre to EoT $(P<0.00 \mathrm{I})$; improvements were maintained from EoT to FU (NS).

HADS (Depression): No significant results between arms (NS); depression $\downarrow$ for all women across time $(P<0.00 \mathrm{I})$.

EORTC QLQ-C30 (Fatigue)': No significant results between arms (NS); fatigue $\downarrow$ for all women across time $(P<0.05)$.

EORTC QLQ-C30 (Insomnia)': Insomnia $\downarrow$ more and at a faster rate in the HT arm than the control $(P<0.00 \mathrm{I})$; insomnia scores $\downarrow$ for all women across time $(P<0.01)$.

Negative affect index (Negative Affect): No significant differences between treatment and placebo (NS), with minimal effect size for low (0.06) and high dose $(0.02)$ treatments, POMS (fatigue): No significant differences between treatment and placebo (NS), with minimal effect sizes for low $(0.03)$ and high $(-0.03)$ dose treatments, PSQI (Sleep Quality): No significant differences between treatment and placebo (NS), but notable effect sizes for low (0.29) and high (0.22) dose treatments.
ND $+$

Hypertension $\quad+$ venlafaxine daily for 6 wks High dose: I wk of $37.5 \mathrm{mg}$ of venlafaxine daily plus 4 wks of $75 \mathrm{mg}$ of venlafaxine daily plus I wk of $37.5 \mathrm{mg}$ of venlafaxine daily

(Continued) 
Table 2 (Continued)

\begin{tabular}{|c|c|c|c|}
\hline Citation & Population description & Description of intervention & Description of control \\
\hline \multicolumn{4}{|l|}{ CAM } \\
\hline Carson et $\mathrm{al}^{61}$ & $\begin{array}{l}37 \text { female breast cancer } \\
\text { survivors ( } \leq \text { Stage IIB) with } \\
\text { a mean age of } 53.9 \pm 9.0(T) \\
\text { and } 54.9 \pm 6.2(\mathrm{C}) \text { years }\end{array}$ & $\begin{array}{l}\text { Yoga awareness (YA): Group classes led by a } \\
\text { certified yoga teacher; each class included gentle } \\
\text { stretching poses, breathing techniques, meditation, } \\
\text { study of pertinent topics, group discussion; } \\
\text { participants encouraged to spend time practicing } \\
\text { yoga at home with the aid of CD recording } \\
\text { and illustrated handbooks } \\
\text { Assessment time points: baseline, } \\
\text { EoT ( } 2 \text { mons), and FU: } 3 \text { mons }\end{array}$ & $\begin{array}{l}\text { Wait list: Participants } \\
\text { invited to participate } \\
\text { in yoga after } 3 \text { mons } \\
\text { assessment }\end{array}$ \\
\hline
\end{tabular}

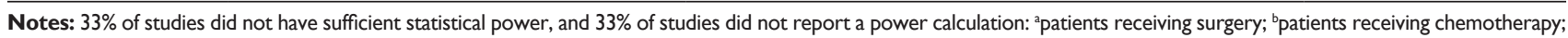
'patients receiving radiation; ${ }^{\mathrm{d}}$ patients receiving surgery, chemotherapy, and radiation; ${ }^{\mathrm{e}}$ patients receiving surgery and chemotherapy; ${ }^{\mathrm{f}}$ patients receiving chemotherapy and radiation; ${ }^{g}$ patients receiving hormone therapy; htreatment received not described; 'effect size not reported; ***Negative affect index was calculated as the combination of standardized scores on four questionnaires: the POMS-Short Form total mood disturbance score (excluding fatigue), the negative affect subscale of the PANAS, the CES-D, and the Ham-D.

Abbreviations: $95 \% \mathrm{Cl}$, 95\% Confidence Interval; BFI, Brief Fatigue Inventory; BSF, Berlin Mood Questionnaire; C, control group; CBT, Cognitive Behavioral Therapy; BDI, Beck Depression Inventory; CES-D, Center for Epidemiological Studies-Depression Scale; CFS, Chalder Fatigue Scale; CHT, chemotherapy; CRF, Case Report Form; EORTC QLC-C30, European Organization for Research and Treatment of Cancer Health Related Quality of Life Questionnaire; EoT, end of treatment; FACIT-F, Functional Assessment of Chronic Illness Therapy; FACT-A, Functional Assessment of Cancer Therapy-Anemia; FSCL, Fatigue Symptom Checklist; FSI, Fatigue Symptom Inventory; FU, follow-up; GBB, Geissen Complaints Inventory; GHQ, General Health Questionnaire; HADS, Hospital Anxiety Depression Score; HDRS, Hamilton Depression Rating Scale; HR, hour; HSCL-25, Hopkins Symptom Checklist-25; ISI, Insomnia Severity Index; MAF, Multidimensional Assessment of Fatigue; MD, mean difference; MDA BFI, Anderson Brief Fatigue Inventory; MFI, Multidimensional Fatigue Inventory; Min, minutes; Mon(s), month(s); MSQ, Mini Sleep Questionnaire; NCl-CTC, National Cancer Institute Common Toxicity Criteria; ND, not described; NFQ, Norwegian Fatigue Questionnaire; NS, not significant; PANAS, Positive and Negative Affect Scale; PFS, Piper Revised Fatigue Scale; POMS-DD, Monopolar Profile of Mood States; POMS, Profile of Mood States; PSQI, Pittsburgh Sleep Quality Index; QOL, quality of life; RT, radiation therapy; reps, repetitions; SAS, Self-rating Anxiety Scale; SCD, Self Care Diary; SD, standard deviation; SE, side effect; SIGN, Scottish Intercollegiate Guidelines Network; T, treatment group; UC, usual care; VDBP, van den Borne and Pruyn; Wk(s), week(s).

measurement as some other scales that focus solely on those respective symptoms.

Our systematic evaluation of the literature concerning quality using the SIGN 50 checklist suggested that overall, studies were of high quality, with over a quarter $(n=12)$ of studies being of poor quality and only a few $(n=4)$ being of very high quality. Studies could generally improve in their reporting of randomization and allocation concealment, as well as ensuring that the reliability and validity of outcomes reported are referenced appropriately. While it is not common practice that subscales of self-report questionnaires are referenced in terms of their reliability and validity, if analyses are conducted and conclusions are to be drawn by authors based on subscale results, we suggest that authors of studies should make reference to the reliability and validity of subscales that they examine. We also note that many studies were limited in their sample size.

Overall GRADE results suggest that, out of the three symptoms we reviewed, the one most likely to improve with treatment is sleep disturbance, with many studies reporting a significant effect on sleep disturbance, regardless of type of intervention. In these studies, sleep disturbance was generally reflected by reduced insomnia, and was generally measured using self-report questionnaires such as the Pittsburgh Sleep Quality Index (PSQI), the Insomnia Severity Index (ISI), and the EORTC-QLQ-30 insomnia subscale. Interventions were generally applied post-surgery, and during the active course of breast cancer treatment (examples are chemotherapy and/or radiation), with duration of treatments ranging from 3 weeks to 2 years, and generally being of about 6 weeks. It is interesting to note that only one study included in the GRADE analysis ${ }^{58}$ utilized an intervention that specifically targeted insomnia. This suggests that self-reported sleep disturbance is a more easily modifiable target in breast cancer patients undergoing active treatment, regardless of the type of intervention. Breast cancer patients report high levels of sleep disturbance at all stages of the breast cancer experience: before diagnosis, after diagnosis and before cancer treatment, during cancer treatment, and even years after the end of cancer treatment. ${ }^{62}$ Persistent and pervasive sleep problems are debilitating, exacerbate physical pain and psychological distress, and have been shown to impair the immune system; disrupting inflammation signaling and the hypothalamic-pituitary-adrenal axis (HPA) stress response. ${ }^{63}$ Hence targeting sleep disturbance might be the fastest way to improve quality of life and health in breast cancer patients, ultimately decreasing recurrence and hence increasing longevity. Future research should test the validity of these hypotheses.

Our GRADE results indicated mixed findings for interventions on improving fatigue, and little support for depression. These results suggest that while the clustering of sleep disturbance, fatigue, and depression is common, the successful treatment of one symptom does not necessarily result into adequate treatment of related symptoms. 


\begin{tabular}{|c|c|c|c|}
\hline Intervention duration & Relevant outcomes assessed/results & Adverse events & Quality \\
\hline $\begin{array}{l}\text { YA: } 8 \times 120 \mathrm{~min} / \mathrm{wk} \text { group } \\
\text { classes for } 8 \text { wks total } \\
- \text { gentle stretching poses } \\
\quad(40 \mathrm{~min}) \\
\text { - breathing techniques } \\
\quad(10 \mathrm{~min}) \\
- \text { meditation }(25 \mathrm{~min}) \\
\text { - study of pertinent topics } \\
\\
\quad(20 \mathrm{~min}) \\
- \text { group discussion }(25 \mathrm{~min})\end{array}$ & $\begin{array}{l}\text { Daily diary (Fatigue) })^{i} \text { YA arm showed greater } \downarrow \text { in fatigue compared } \\
\text { to the control at EoT }(P<0.0 \mathrm{I}) \text { and FU }(P<0.0 \mathrm{I}) \text {. } \\
\text { Daily diary (Negative Mood): No differences in negative mood between arms } \\
\text { at EoT (NS) but YA showed greater improvement compared to control } \\
\text { at FU ( } P<0.00 \mathrm{I}) \text {. } \\
\text { Daily diary (Sleep Disturbance) })^{\text {i }} \text { YA showed greater } \downarrow \text { in sleep disturbance } \\
\text { compared to control at EoT }(P<0.0 \mathrm{I}) \text { but not at FU (NS). }\end{array}$ & ND & + \\
\hline
\end{tabular}

Findings suggested that reduction of fatigue sometimes, but not always, followed successful reduction of insomnia in breast cancer patients. The strong co-morbidity of fatigue and sleep disturbance has been previously noted in terms of its occurrence prior to, during, and after active treatment for cancer, ${ }^{2,64,65}$ with some studies suggesting some commonality in dysregulation of inflammatory pathways ${ }^{9,66,67}$ associated with fatigue and sleep disturbance during treatment. However, persistent fatigue is also associated with HPA axis dysregulation, ${ }^{7}$ which may require other forms of

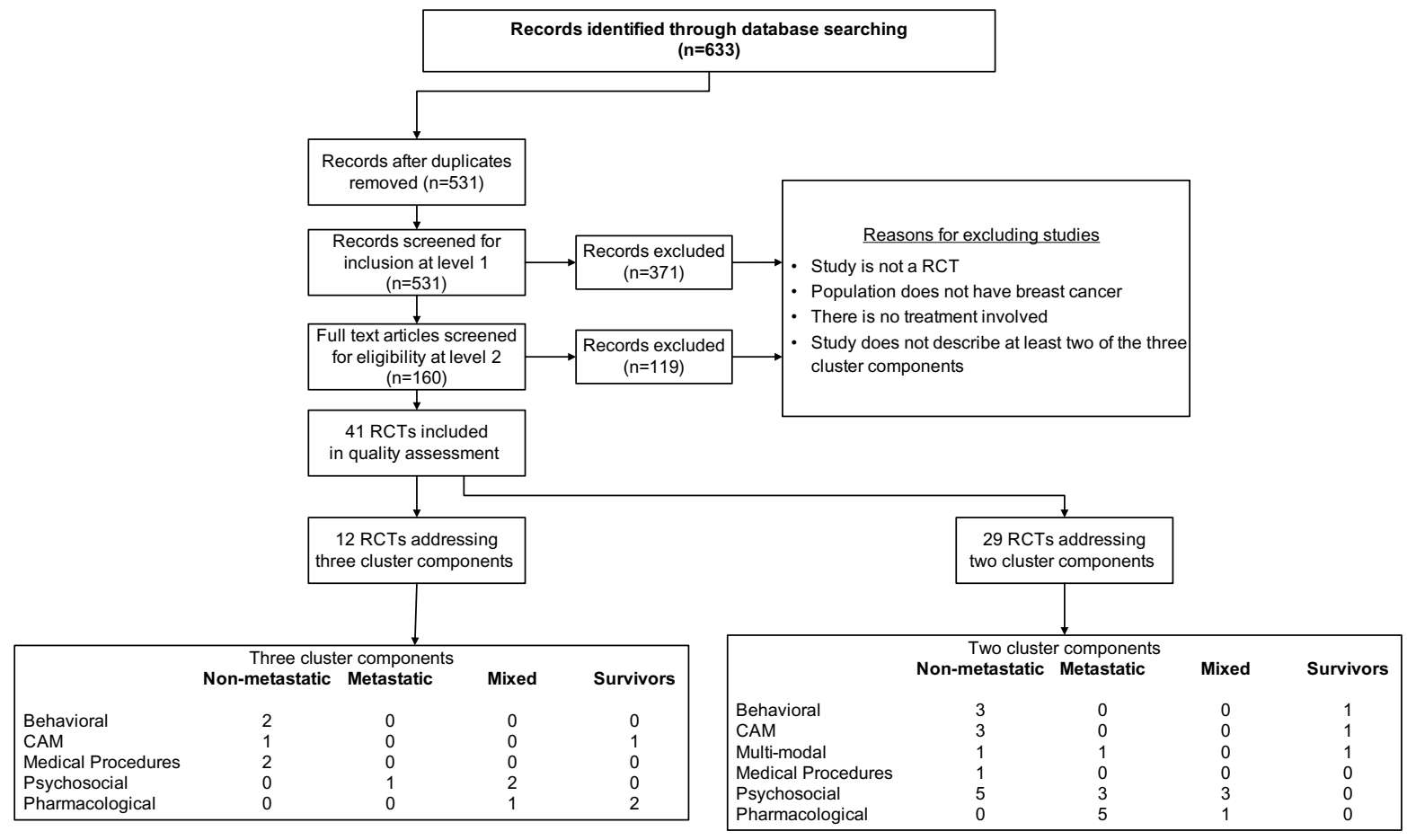

Figure 2 Flow chart.

Abbreviations: CAM, complementary/alternative medicine; RCT, randomized controlled trial. 
Table 3 GRADE analysis: quality of the overall literature pool by population/intervention type for studies assessing three cluster components

\begin{tabular}{|c|c|c|c|c|c|c|}
\hline Condition & $\begin{array}{l}\text { Number of participants } \\
\text { completed (number } \\
\text { of studies) }\end{array}$ & $\begin{array}{l}\text { Confidence in } \\
\text { estimate of } \\
\text { effect GRADE }\end{array}$ & $\begin{array}{l}\text { Magnitude of } \\
\text { estimate of } \\
\text { effect GRADE }\end{array}$ & $\begin{array}{l}\text { Safety } \\
\text { GRADE }\end{array}$ & $\begin{array}{l}\text { GRADE } \\
\text { recommendation }\end{array}$ & Comments \\
\hline \multicolumn{7}{|l|}{ Metastatic $(n=1)$} \\
\hline Psychosocial* & - & - & - & - & - & - \\
\hline \multicolumn{7}{|c|}{ Non-metastatic $(n=5)$} \\
\hline Behavioral & $70(2)$ & C & ND & 0 & No recommendation & $\begin{array}{l}\text { Some promise for sleep, } \\
\text { mixed for fatigue, neither } \\
\text { statistically significant on } \\
\text { depression. Both poor } \\
\text { quality (-,-) studies and } \\
\text { under-powered. }\end{array}$ \\
\hline Pharmacological & $558(2)$ & B & ND & 0 & $\begin{array}{l}\text { Weak } \\
\text { recommendation } \\
\text { in favor }\end{array}$ & $\begin{array}{l}\text { Promising for sleep, mixed } \\
\text { for fatigue, and neither } \\
\text { statistically significant for } \\
\text { depression. Mixed quality } \\
\text { studies (+,-). }\end{array}$ \\
\hline CAM* $^{*}$ & - & - & - & - & - & - \\
\hline \multicolumn{7}{|l|}{ Mixed $(n=3)$} \\
\hline Psychosocial & $237(2)$ & B & ND & 0 & $\begin{array}{l}\text { Weak } \\
\text { recommendation } \\
\text { in favor }\end{array}$ & $\begin{array}{l}\text { Promising for sleep, mixed } \\
\text { for depression and not } \\
\text { statistically significant for } \\
\text { fatigue. Adequate quality } \\
\text { studies }(+,+) \text {. }\end{array}$ \\
\hline Pharmacological* & - & - & - & - & - & - \\
\hline \multicolumn{7}{|l|}{ Survivors $(n=3)$} \\
\hline Pharmacological & $145(2)$ & B & ND & 0 & No recommendation & $\begin{array}{l}\text { Promising for sleep, no } \\
\text { evidence for depression } \\
\text { or fatigue. Mixed quality } \\
\text { studies }(+,-) \text {. }\end{array}$ \\
\hline $\mathrm{CAM}^{*}$ & - & - & - & - & - & - \\
\hline
\end{tabular}

Notes: *Due to the small number of studies in these categories, four studies ${ }^{35,40,42,43}$ were not assessed via the GRADE; There are four major domains that comprise the core of the modified GRADE methodology: (I) confidence in the estimate of the effect was categorized into the following groups using pre-defined criteria: A) High: further research is very unlikely to change confidence in the estimate of effect; several high quality RCTs with consistent results or in special cases, or one large, high quality, multicenter RCT; B) Moderate: further research is likely to have an important impact on confidence in the estimate of effect and may change the estimate; one high quality RCT or several RCTs with some limitations; C) Low: further research is very likely to have an important impact on confidence in the estimate of effect and is likely to change the estimate; one or more RCTs with severe limitations; D) Very Low: any estimate of effect is very uncertain; expert opinion, no direct research evidence or one or more RCTs with severe limitations. (2) magnitude of the effect was categorized into five levels of none $(<0.2)$, small $(0.2-0.5)$, moderate $(0.5-0.8)$, large $(>0.8)$, or not described (authors did not describe or report effect size for this review's outcomes of interest due to the lack of author reporting). (3) safety grade is dependent on the frequency and severity of adverse events and interactions. Safety was categorized into one of the following grades: +2 , appears safe with infrequent adverse events and interactions; +1 , appears relatively safe but with frequent but not serious adverse events and interactions; 0 , safety not well understood or conflicting; $-\mathrm{I}$, appears to have safety concerns that include infrequent but serious adverse events and/or interactions or; -2 , has serious safety concerns that include frequent and serious adverse events and/or interactions. (4) strength of the recommendation can be determined using the following categories and criteria: strong recommendation in favor of or against - very certain that benefits do, or do not, outweigh risks and burdens; no recommendation - no recommendations can be made or; weak recommendation in favor of or against - benefits and risks and burdens are finely balanced, or appreciable uncertainty exists about the magnitude of benefits and risks.

Abbreviations: CAM, complementary/alternative medicine; GRADE, Grading of Recommendation Assessment, Development and Evaluation; RCT, randomized controlled trial.

intervention in addition to modifying sleep. Results for the concomitant modification of depression along with sleep were not promising. Interestingly, depression was more likely to improve with improvements in fatigue, although generally speaking, depression was the least likely symptom of the three to improve during the study period. This suggests that while depression often occurs with fatigue and sleep disturbance during cancer treatment, it may be harder to treat effectively, especially during the course of breast cancer therapy. These findings echo similar conclusions derived from meta-analyses of psychological and pharmacological therapies for depression, where evidence appears mixed for pharmacotherapy, and while somewhat promising for certain psychosocial approaches, is still relatively limited in certain cancer populations. ${ }^{68,69}$

We note that the majority of our studies generally focused on interventions of a single modality, such as a sole behavioral (exercise), psychosocial (psychotherapy), complementary medicine (herb), or pharmacological (drug) treatment. It is unknown, however, whether more integrative, multi-modal 
treatments that focus on all aspects of the person and therefore address more than one symptom at once (ie, a multi-modal or "whole systems" approach) may show more promise in being able to effectively treat the symptom cluster to enable breast cancer patients to achieve and maintain a healthier and more regulated state during and after treatment. Multimodal treatment options, as compared to single modality treatments, have emerged as an important option in the management of many disorders and have the potential to simultaneously address the dynamic nature of the disease process over time. It is the authors' recommendation that future studies consider more multi-modal or whole-systems approaches to addressing these types of symptom clusters associated with disease states.

There are limitations associated with this systematic review. First, because this is a Rapid Evidence Assessment of the Literature, the authors only examined the RCT study designs reported on in the English language to explore this research question. Second, due to the general lack of studies reporting examination of all three symptoms examined in the review, and the challenge of existing studies having inadequate power and lack of adverse events reporting, it is challenging to make recommendations about particular types of interventions for this symptom cluster. While we were able to extract data for the studies that included two of the three symptoms as outcomes, we were unable to conduct the GRADE on studies that reported only two of the three symptoms for this review, and this may be seen as a limitation. However, our primary objective was to determine the impact of interventions that addressed all three components of the targeted symptom cluster of depression, fatigue, and sleep disturbance. The information from this review may guide further reviews that may choose to examine more specifically the impact of interventions on two of the three symptoms (such as fatigue and sleep disturbance). We encourage researchers in the field to take into consideration where we have noted the quality of reporting can be improved in future studies and some of the interventions, outcomes, and symptom cluster relationships that we have discovered throughout this process to produce powerful results in future work.

\section{Conclusion}

In summary, results from our systematic review, using the REAL $^{\circ}$ process, suggest that among the clustered symptoms of fatigue, sleep disturbance, and depression, sleep disturbance appears to be the symptom that responds best to interventions currently studied, with some studies also showing promise for fatigue. It is unclear whether treatment of sleep disturbance will necessarily result in effective improvements in other symptoms. Results also suggest that compared to sleep disturbance and fatigue, depression may be more difficult to treat for breast cancer patients and that treatment of sleep disturbance and fatigue do not necessarily translate to adequate treatment of depression. We highly recommend that future studies examine the psychometric and clinical validity of the hypothesized relationship among the sleep/ fatigue/depression symptom cluster in breast cancer patients, including examining the relationships of these symptoms over time. In addition we encourage the development and testing of new treatment modalities, including multi-modal treatments, which may prove to be more efficacious than those presently studied for this cluster of symptoms.

\section{Acknowledgments}

The authors have not presented this data and information before in any journal. This data was presented in a poster at the MASCC/ISOO International Symposium on Supportive Care in Cancer in June $2012^{70}$ as well as at the American Psychosocial Oncology Society in February 2013. ${ }^{71}$ The authors have no professional relationships with companies or manufacturers who will benefit from the results of this present study. This material is based upon work supported by the US Army Medical Research and Materiel Command under Award No W81XWH-06-1-0279. Any opinions, findings, and conclusions or recommendations expressed in this material are those of the author(s) and should not be construed as an official Department of the Army position, policy, or decision unless so designated by other documentation.

\section{Disclosure}

The authors report no conflicts of interest in this work.

\section{References}

1. DeSantis C, Siegel R, Bandi P, Jemal A. Breast cancer statistics, 2011. CA Cancer J Clin. 2011;61(6):409-418.

2. Liu L, Rissling M, Natarajan L, et al. The longitudinal relationship between fatigue and sleep in breast cancer patients undergoing chemotherapy. Sleep. 2012;35(2):237-245.

3. Fiorentino L, Rissling M, Liu L, Ancoli-Israel S. The Symptom Cluster of Sleep, Fatigue and Depressive Symptoms in Breast Cancer Patients: Severity of the Problem and Treatment Options. Drug Discov Today Dis Models. 2011;8(4):167-173.

4. Bower JE, Ganz PA, Irwin MR, Kwan L, Breen EC, Cole SW. Inflammation and behavioral symptoms after breast cancer treatment: do fatigue, depression, and sleep disturbance share a common underlying mechanism? J Clin Oncol. 2011;29(26):3517-3522.

5. Aktas A, Walsh D, Rybicki L. Symptom clusters: myth or reality? Palliat Med. 2010;24(4):373-385.

6. Kirkova J, Aktas A, Walsh D, Davis MP. Cancer symptom clusters: clinical and research methodology. J Palliat Med. 2011;14(10): 1149-1166. 
7. Jain S, Irwin MR, Bower J. Psychoneuroimmunology of Fatigue and Sleep Disturbance: The role of Pro-Inflammatory Cytokines. In: Segerstrom S, editor. Oxford Handbook of Psychoneuroimmunology. Oxford: Oxford University Press; 2012:319-340.

8. Miller AH, Ancoli-Israel S, Bower JE, Capuron L, Irwin MR. Neuroendocrine-immune mechanisms of behavioral comorbidities in patients with cancer. J Clin Oncol. 2008;26(6):971-982.

9. Liu L, Mills PJ, Rissling M, et al. Fatigue and sleep quality are associated with changes in inflammatory markers in breast cancer patients undergoing chemotherapy. Brain Behav Immun. 2012;26(5):706-713.

10. Dantzer R, O'Connor JC, Freund GG, Johnson RW, Kelley KW. From inflammation to sickness and depression: when the immune system subjugates the brain. Nat Rev Neurosci. 2008;9(1):46-56.

11. Collado-Hidalgo A, Bower JE, Ganz PA, Irwin MR, Cole SW. Cytokine gene polymorphisms and fatigue in breast cancer survivors: early findings. Brain Behav Immun. 2008;22(8):1197-1200.

12. Liu L, Fiorentino L, Natarajan L, et al. Pre-treatment symptom cluster in breast cancer patients is associated with worse sleep, fatigue and depression during chemotherapy. Psychooncology. 2009;18(2):187-194.

13. Dodd MJ, Cho MH, Cooper BA, Miaskowski C. The effect of symptom clusters on functional status and quality of life in women with breast cancer. Eur J Oncol Nurs. 2010;14(2):101-110.

14. Golan-Vered Y, Pud D. Chemotherapy-induced neuropathic pain and its relation to cluster symptoms in breast cancer patients treated with paclitaxel. Pain Pract. 2013;13(1):46-52.

15. Kim HJ, Barsevick AM, Beck SL, Dudley W. Clinical subgroups of a psychoneurologic symptom cluster in women receiving treatment for breast cancer: a secondary analysis. Oncol Nurs Forum. 2012;39(1): E20-E30.

16. Lee C, Crawford C, Wallerstedt D, et al. The effectiveness of acupuncture research across components of the trauma spectrum response (tsr): a systematic review of reviews. Syst Rev. 2012;1:46.

17. York A, Crawford C, Walter A, Walter J, Jonas W, Coeytaux R. Acupuncture research in military and veteran populations: A Rapid Evidence Assessment of the Literature. Med Acupuncture. 2011;23(4): 229-236.

18. McGowan J, Sampson M. Systematic reviews need systematic searchers. J Med Libr Assoc. 2005;93(1):74-80.

19. Scottish Intercollegiate Guidelines Network (SIGN). SIGN 50: A Guideline Developer's Handbook. SIGN; 2001. Available from: http://www.sign.ac.uk/methodology/checklists.html. Accessed December 31, 2013.

20. Grading of Recommendations Assessment, Development and Evaluation (GRADE). Available from: http://www.gradeworkinggroup.org/ INTRO.HTM. Accessed September 28, 2010.

21. Bottomley A, Biganzoli L, Cufer T, et al; European Organization for Research and Treatment of Cancer Breast Cancer Group. Randomized, controlled trial investigating short-term health-related quality of life with doxorubicin and paclitaxel versus doxorubicin and cyclophosphamide as first-line chemotherapy in patients with metastatic breast cancer: European Organization for Research and Treatment of Cancer Breast Cancer Group, Investigational Drug Branch for Breast Cancer and the New Drug Development Group Study. J Clin Oncol. 2004;22(13):2576-2586.

22. Svensson H, Einbeigi Z, Johansson H, Hatschek T, Brandberg Y. Quality of life in women with metastatic breast cancer during 9 months after randomization in the TEX trial (epirubicin and paclitaxel w/o capecitabine). Breast Cancer Res Treat. 2010;123(3):785-793.

23. Hakamies-Blomqvist L, Luoma M, Sjöström J, et al. Quality of life in patients with metastatic breast cancer receiving either docetaxel or sequential methotrexate and 5-fluorouracil. A multicentre randomised phase III trial by the Scandinavian breast group. Eur J Cancer. 2000;36(11):1411-1417.

24. Diel IJ, Body JJ, Lichinitser MR, et al; MF 4265 Study Group. Improved quality of life after long-term treatment with the bisphosphonate ibandronate in patients with metastatic bone disease due to breast cancer. Eur J Cancer. 2004;40(11):1704-1712.
25. Geels P, Eisenhauer E, Bezjak A, Zee B, Day A. Palliative effect of chemotherapy: objective tumor response is associated with symptom improvement in patients with metastatic breast cancer. J Clin Oncol. 2000;18(12):2395-2405.

26. Bordeleau L, Szalai JP, Ennis M, et al. Quality of life in a randomized trial of group psychosocial support in metastatic breast cancer: overall effects of the intervention and an exploration of missing data. J Clin Oncol. 2003;21(10):1944-1951.

27. Williams SA, Schreier AM. The role of education in managing fatigue, anxiety, and sleep disorders in women undergoing chemotherapy for breast cancer. Appl Nurs Res. 2005;18(3):138-147.

28. Low CA, Stanton AL, Bower JE, Gyllenhammer L. A randomized controlled trial of emotionally expressive writing for women with metastatic breast cancer. Health Psychol. 2010;29(4):460-466.

29. Targ EF, Levine EG. The efficacy of a mind-body-spirit group for women with breast cancer: a randomized controlled trial. Gen Hosp Psychiatry. 2002;24(4):238-248.

30. Bonnema J, van Wersch AM, van Geel AN, et al. Medical and psychosocial effects of early discharge after surgery for breast cancer: randomised trial. BMJ. 1998;316(7140):1267-1271.

31. Courneya KS, Segal RJ, Mackey JR, et al. Effects of aerobic and resistance exercise in breast cancer patients receiving adjuvant chemotherapy: a multicenter randomized controlled trial. J Clin Oncol. 2007;25(28):4396-4404.

32. Wang YJ, Boehmke M, Wu YW, Dickerson SS, Fisher N. Effects of a 6-week walking program on Taiwanese women newly diagnosed with early-stage breast cancer. Cancer Nurs. 2011;34(2):E1-E13.

33. Mock V, Pickett M, Ropka ME, et al. Fatigue and quality of life outcomes of exercise during cancer treatment. Cancer Pract. 2001;9(3): 119-127.

34. Listing M, Krohn M, Liezmann C, et al. The efficacy of classical massage on stress perception and cortisol following primary treatment of breast cancer. Arch Womens Ment Health. 2010;13(2):165-173.

35. Listing M, Reisshauer A, Krohn M, et al. Massage therapy reduces physical discomfort and improves mood disturbances in women with breast cancer. Psychooncology. 2009;18(12):1290-1299.

36. da Costa Miranda V, Trufelli DC, Santos J, et al. Effectiveness of guaraná (Paullinia cupana) for postradiation fatigue and depression: results of a pilot double-blind randomized study. J Altern Complement Med. 2009;15(4):431-433.

37. Berger AM, Kuhn BR, Farr LA, et al. Behavioral therapy intervention trial to improve sleep quality and cancer-related fatigue. Psychooncology. 2009;18(6):634-646.

38. Cohen M, Fried G. Comparing relaxation training and cognitivebehavioral group therapy for women with breast cancer. Res Social Work Prac. 2007;17(3):313-323.

39. Badger T, Segrin C, Meek P, Lopez AM, Bonham E, Sieger A. Telephone interpersonal counseling with women with breast cancer: symptom management and quality of life. Oncol Nurs Forum. 2005; 32(2):273-279.

40. Sandgren AK, McCaul KD, King B, O'Donnell S, Foreman G. Telephone therapy for patients with breast cancer. Oncol Nurs Forum. 2000;27(4):683-688.

41. Dolbeault S, Cayrou S, Brédart A, et al. The effectiveness of a psycho-educational group after early-stage breast cancer treatment: results of a randomized French study. Psychooncology. 2009;18(6): 647-656.

42. Lindemalm C, Mozaffari F, Choudhury A, et al. Immune response, depression and fatigue in relation to support intervention in mammary cancer patients. Support Care Cancer. 2008;16(1):57-65.

43. Roscoe JA, Morrow GR, Hickok JT, et al. Effect of paroxetine hydrochloride (Paxil) on fatigue and depression in breast cancer patients receiving chemotherapy. Breast Cancer Res Treat. 2005;89(3):243-249.

44. Thornton LM, Andersen BL, Schuler TA, Carson WE. A psychological intervention reduces inflammatory markers by alleviating depressive symptoms: secondary analysis of a randomized controlled trial. Psychosom Med. 2009;71(7):715-724. 
45. Sandgren AK, McCaul KD. Long-term telephone therapy outcomes for breast cancer patients. Psychooncology. 2007;16(1):38-47.

46. Jain S, Pavlik D, Distefan J, et al. Complementary medicine for fatigue and cortisol variability in breast cancer survivors: a randomized controlled trial. Cancer. 2012;118(3):777-787.

47. Lee SA, Kang JY, Kim YD, et al. Effects of a scapula-oriented shoulder exercise programme on upper limb dysfunction in breast cancer survivors: a randomized controlled pilot trial. Clin Rehabil. 2010;24(7): 600-613.

48. Kim SH, Shin MS, Lee HS, et al. Randomized pilot test of a simultaneous stage-matched exercise and diet intervention for breast cancer survivors. Oncol Nurs Forum. 2011;38(2):E97-E106.

49. Sandgren AK, McCaul KD. Short-term effects of telephone therapy for breast cancer patients. Health Psychol. 2003;22(3):310-315.

50. Savard J, Simard S, Giguère I, et al. Randomized clinical trial on cognitive therapy for depression in women with metastatic breast cancer: psychological and immunological effects. Palliat Support Care. 2006;4(3):219-237.

51. Prescott RJ, Kunkler IH, Williams LJ, et al. A randomised controlled trial of postoperative radiotherapy following breast-conserving surgery in a minimum-risk older population. The PRIME trial. Health Technol Assess. 2007;11(31):1-149, iii.

52. Groenvold M, Fayers PM, Petersen MA, Mouridsen HT. Chemotherapy versus ovarian ablation as adjuvant therapy for breast cancer: impact on health-related quality of life in a randomized trial. Breast Cancer Res Treat. 2006;98(3):275-284.

53. de Oliveira Campos MP, Riechelmann R, Martins LC, Hassan BJ, Casa FB, Del Giglio A. Guarana (Paullinia cupana) improves fatigue in breast cancer patients undergoing systemic chemotherapy. J Altern Complement Med. 2011;17(6):505-512.

54. Payne JK, Held J, Thorpe J, Shaw H. Effect of exercise on biomarkers, fatigue, sleep disturbances, and depressive symptoms in older women with breast cancer receiving hormonal therapy. Oncol Nurs Forum. 2008;35(4):635-642.

55. Mock V, Pickett M, Ropka ME, et al. Fatigue and quality of life outcomes of exercise during cancer treatment. Cancer Pract. 2001;9(3): $119-127$.

56. van Dam FS, Schagen SB, Muller MJ, et al. Impairment of cognitive function in women receiving adjuvant treatment for high-risk breast cancer: high-dose versus standard-dose chemotherapy. J Natl Cancer Inst. 1998;90(3):210-218.

57. Arving C, Sjödén PO, Bergh J, et al. Individual psychosocial support for breast cancer patients: a randomized study of nurse versus psychologist interventions and standard care. Cancer Nurs. 2007;30(3):E10-E19.

58. Savard J, Simard S, Ivers H, Morin CM. Randomized study on the efficacy of cognitive-behavioral therapy for insomnia secondary to breast cancer, part II: Immunologic effects. J Clin Oncol. 2005;23(25): 6097-6106.

59. Fahlén M, Wallberg B, von Schoultz E, et al. Health-related quality of life during hormone therapy after breast cancer: a randomized trial. Climacteric. 2011;14(1):164-170.
60. Carpenter JS, Storniolo AM, Johns S, et al. Randomized, double-blind, placebo-controlled crossover trials of venlafaxine for hot flashes after breast cancer. Oncologist. 2007;12(1):124-135.

61. Carson JW, Carson KM, Porter LS, Keefe FJ, Seewaldt VL. Yoga of Awareness program for menopausal symptoms in breast cancer survivors: results from a randomized trial. Support Care Cancer. 2009;17(10):1301-1309.

62. Fiorentino L, Ancoli-Israel S. Insomnia and its treatment in women with breast cancer. Sleep Med Rev. 2006;10(6):419-429.

63. Vgontzas AN, Chrousos GP. Sleep, the hypothalamic-pituitary-adrenal axis, and cytokines: multiple interactions and disturbances in sleep disorders. Endocrinol Metab Clin North Am. 2002;31(1):15-36.

64. Ancoli-Israel S, Liu L, Marler MR, et al. Fatigue, sleep, and circadian rhythms prior to chemotherapy for breast cancer. Support Care Cancer 2006;14(3):201-209.

65. Van Onselen C, Cooper BA, Lee K, et al. Identification of distinct subgroups of breast cancer patients based on self-reported changes in sleep disturbance. Support Care Cancer. 2012;20(10):2611-2619.

66. Wang XS, Shi Q, Williams LA, et al. Inflammatory cytokines are associated with the development of symptom burden in patients with NSCLC undergoing concurrent chemoradiation therapy. Brain Behav Immun. 2010;24(6):968-974.

67. Kim HJ, Barsevick AM, Fang CY, Miaskowski C. Common biological pathways underlying the psychoneurological symptom cluster in cancer patients. Cancer Nurs. 2012;35(6):E1-E20.

68. Li M, Fitzgerald P, Rodin G. Evidence-based treatment of depression in patients with cancer. J Clin Oncol. 2012;30(11):1187-1196.

69. Osborn RL, Demoncada AC, Feuerstein M. Psychosocial interventions for depression, anxiety, and quality of life in cancer survivors: metaanalyses. Int J Psychiatry Med. 2006;36(1):13-34.

70. Jain S, Fiorentino L, Lee C, Khorsan R, Jonas W. Are there efficacious treatments for treating Fatigue-Sleep Disturbance-Depression Symptom Cluster In Breast Cancer Patients: A Rapid Evidence Assessment of the Literature (REAL). MASCC/ISOO 2012 International Symposium. New York, NY; June 28-30, 2012.

71. Jain S, Fiorentino L, Lee C, Crawford C, Khorsan R, Jonas WB. A Rapid Evidence Assessment $\left(\mathrm{REAL}^{\circ}\right)$ of the Literature: Are there efficacious treatments for treating the fatigue-sleep disturbance-depression symptom cluster in breast cancer patients? Paper presented at: American Psychosocial Oncology Society. Huntington Beach, CA; February 13-15, 2013.

72. Crawford C, Wallerstedt DB, Khorsan R, Clausen SS, Jonas WB, Walter JA. A systematic review of biopsychosocial training programs for the self-management of emotional stress: potential applications for the military. Evid Based Complement Alternat Med. 2013;747694. Epub 2013 Sep 23.
Breast Cancer: Targets and Therapy

\section{Publish your work in this journal}

Breast Cancer: Targets and Therapy is an international, peerreviewed open access journal focusing on breast cancer research, identification of therapeutic targets and the optimal use of preventative and integrated treatment interventions to achieve improved outcomes, enhanced survival and quality of life for the cancer patient.

\section{Dovepress}

View the full aims and scopes of this journal here. The manuscript management system is completely online and includes a very quick and fair peer-review system, which is all easy to use. Visit http:// www.dovepress.com/testimonials.php to read real quotes from published authors. 